

\title{
Progress in Understanding Low-Temperature Organic Compound Oxidation Using a Jet-Stirred Reactor
}

Olivier Herbinet, Frédérique Battin-Leclerc

\section{To cite this version:}

Olivier Herbinet, Frédérique Battin-Leclerc. Progress in Understanding Low-Temperature Organic Compound Oxidation Using a Jet-Stirred Reactor. International Journal of Chemical Kinetics, 2014, 46 (10), pp.619-639. 10.1002/kin.20871 . hal-01059915

\section{HAL Id: hal-01059915 https://hal.science/hal-01059915}

Submitted on 2 Sep 2014

HAL is a multi-disciplinary open access archive for the deposit and dissemination of scientific research documents, whether they are published or not. The documents may come from teaching and research institutions in France or abroad, or from public or private research centers.
L'archive ouverte pluridisciplinaire HAL, est destinée au dépôt et à la diffusion de documents scientifiques de niveau recherche, publiés ou non, émanant des établissements d'enseignement et de recherche français ou étrangers, des laboratoires publics ou privés. 


\title{
Progress in Understanding Low-Temperature Organic Compound Oxidation Using a Jet-Stirred Reactor
}

\author{
Olivier Herbinet, Frédérique Battin-Leclerc* \\ Laboratoire Réactions et Génie des Procédés, Université de Lorraine, CNRS, ENSIC, \\ BP 20451, 1 rue Grandville, 54000 Nancy, France
}

\begin{abstract}
The jet-stirred reactor (JSR) has become a tool frequently used to study the oxidation of a wide range of reactants and particularly to obtain data for testing detailed kinetic models. This paper aims to discuss recent knowledge pertaining to low-temperature oxidation of hydrocarbons and oxygenated reactants that has been gained from using a JSR in connection with gas chromatography, especially for the detailed quantification of cyclic ethers. Furthermore, JSR in conjunction with mass spectrometry has been applied to the detection of hydroperoxides, including ketohydroperoxides, acids, and compounds with two carbonyl functions. Finally, along with optical diagnostics, JSR has notably been used for the detection of hydrogen peroxide and $\mathrm{OH}$ and $\mathrm{HO}_{2}$ radicals. These aspects are also discussed here.
\end{abstract}

\footnotetext{
* Corresponding author: frederique.battin-leclerc@univ-lorraine.fr
} 


\section{Introduction}

To facilitate the design of new types of engines, such as low-temperature combustion (LTC) diesel or homogeneous charge compression ignition engines [1], it is important to improve the understanding of low-temperature gas phase oxidation of the wide range of organic compounds that can be found in fuels and biofuels. Such an improvement in understanding requires the experimental quantification of the wide range of intermediates and products formed during combustion or oxidation processes. A good prediction of the formation of minor pollutants, such as aldehydes, carboxylic acids, or polycyclic aromatic hydrocarbons (PAHs) is especially of importance to preserve air quality [2].

As described in a previous review [2], three main types of apparatus are used to produce the experimental data required to validate the detailed kinetic models that describe the low-temperature oxidation of organic compounds: rapid compression machines, shock tubes, and heated continuous flow reactors, such as flow tubes or jet-stirred reactors (JSR). Rapid compression machines and shock tubes are useful to provide information about global combustion parameters, such as ignition delay times. However their potential to give reliable quantification of the numerous species produced is limited: Experimental uncertainties arise from temperature gradients in rapid compression machines [3], and shock tube species measurements are only performed from $1100 \mathrm{~K}$ upwards [4]. Both types of heated flow reactors can be used to gain information about global reactivity and also about the formation of a wide range of products. Examples of low-temperature product measurements performed in flow tubes can be found in papers of the teams of Cernansky [5] and Dryer [6]. However, the determination of initial conditions and temperature profiles is certainly a significant source of uncertainty in flow tubes, which does not exist in JSR. Indeed JSR [7] is an extremely suitable tool to study complex reactions under isothermal conditions at constant pressure, initial mixture composition, and residence time, facilitating modeling the data obtained.

Ignition delay times measured in shock tubes [8] and in rapid compression machines [9] have been considered for many years as choice data for the validation of detailed kinetic models of lowtemperature oxidation [10-12]. Nevertheless, for the past few years, the JSR results have been increasingly used to develop and test such models. This is especially the case for reactants with a low vapor pressure [13]. JSR data for methyl palmitate [14] and methyl oleate [15] allowed the first validation of models that take into account the role of double bonds during low-temperature oxidation of methyl esters present in biodiesel [16]. JSR measurements have also recently made possible the validation of a model of the low-temperature oxidation of $\mathrm{C}_{10+}$ alkylbenzenes that are representative of aromatic species present in diesel fuel [17]. 
After recalling a few basic facts about the chemistry involved, this paper aims to describe the recent experimental work using JSR that has been performed to study low-temperature (below $750 \mathrm{~K}$ ) oxidation of hydrocarbons and oxygenated molecules. The second part describes the studies published in the literature on the subject since 1990 and discusses the uncertainties related to the use of JSR. The chemical knowledge that has been gained from these studies, according to the type of analytical techniques used in connection with JSR is detailed in parts on gas chromatography, mass spectrometry, and optical methods.

\section{Generalities about low-temperature oxidation}

Since the 1980s, many studies worldwide have focused on modeling low-temperature oxidation of the constituents of fossil fuels and of mixtures of several of them, which have been proposed as surrogates for current fuels. Several review papers discuss these models and the main elementary steps involved [18-20]. Figure 1 shows a simplified schema of the main reactions that are now generally accepted to model the oxidation of an alkane $(\mathrm{RH})$ whose structure may be linear, branched, or cyclic.

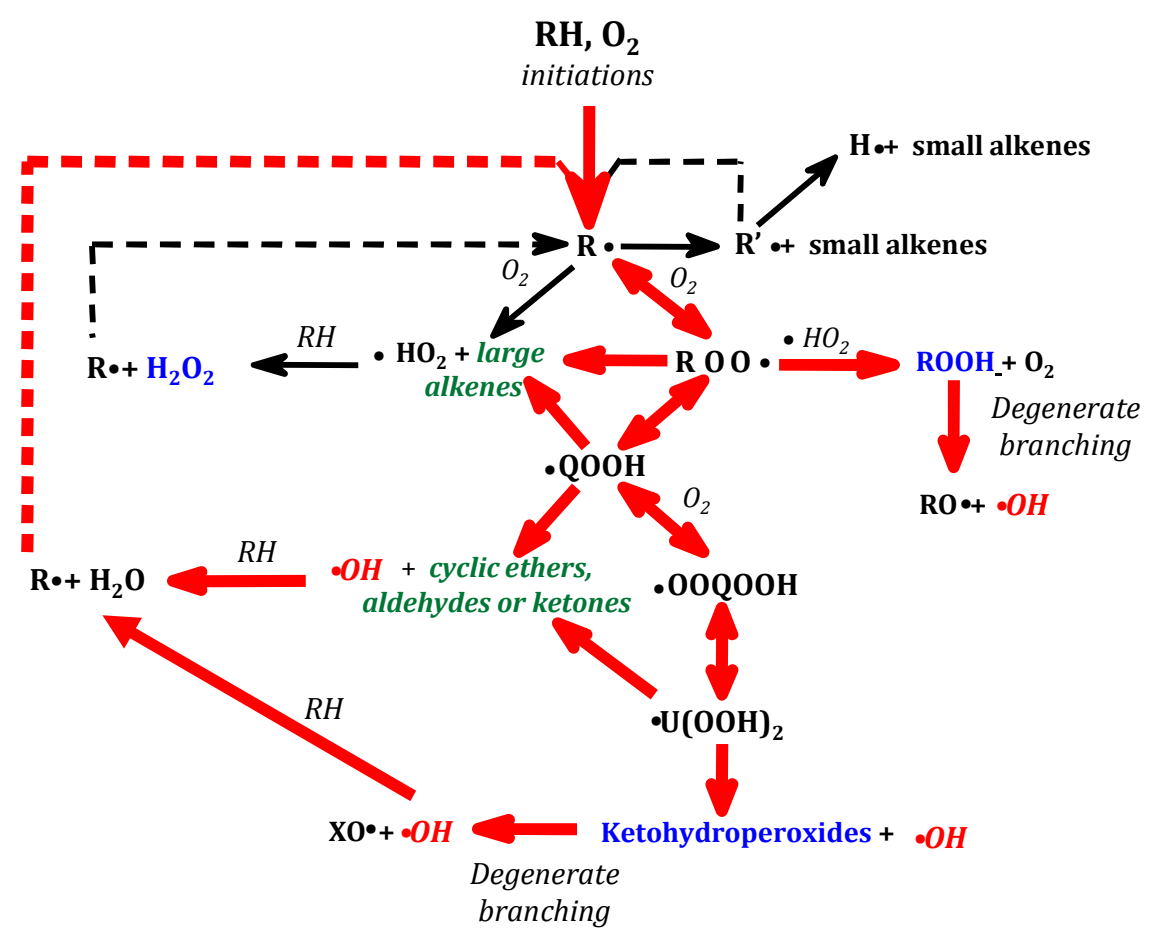

Figure 1. Simplified schema of the primary mechanism of oxidation of alkanes. The thick red arrows indicate the reactions of importance at low temperature. The bold blue species are the molecules whose formation promotes the global reactivity. The green species in bold italics are the products commonly formed during JSR low-temperature oxidation. 
The same type of chemistry is involved in the low-temperature oxidation of large saturated methyl esters, alcohols and ethers, with very few reactions being really specific to these oxygenated reactants, as discussed by Tran et al. [21]. The differences are more significant in the case of alkenes [22] and still more so in the case of aromatics [23].

Except at very high temperatures (above $1200 \mathrm{~K}$ ), the reaction is initiated by the abstraction of an $\mathrm{H}$-atom from the alkane $(\mathrm{RH})$ by oxygen molecules to give alkyl $(\bullet \mathrm{R})$ and hydroperoxy $(\bullet \mathrm{OOH})$ radicals.

At low temperatures (around 500-600 K), alkyl radicals react rapidly with oxygen molecules to give peroxyalkyl radicals (ROO•) that can further undergo several types of reactions, including a series of two isomerizations (ROO• radicals giving $\bullet \mathrm{QOOH}$ radicals and $\bullet \mathrm{OOQOOH}$ radicals giving $\bullet \cup(\mathrm{OOH}) 2$ radicals) as is shown in Figure 1. These reactions lead to the formation of alkylhydroperoxide (ROOH) and ketohydroperoxide species, and of small radicals, such as hydroxyl radicals $(\bullet \mathrm{OH})$, which react with alkane molecules by metatheses to regenerate alkyl radicals. Both types of hydroperoxides are key species that explain the high reactivity of alkanes at low temperature and the occurrence of autoignition. As they include an $\mathrm{O}-\mathrm{OH}$ bond, hydroperoxides can easily decompose, with the formation of two radicals. In their turn, these react with alkane molecules to give alkyl radicals. An exponential acceleration of the reaction rate is then produced by multiplication of the numbers of radicals occurring via these degenerate branching steps.

Owing to the reversibility of the addition of alkyl radicals to oxygen molecules, when temperature increases the formation of alkenes is favored, the overall reaction rate is reduced and the so-called negative temperature coefficient (NTC) regime appears. This distinctive feature of the oxidation of hydrocarbons, which is an area of temperature in which the global reaction rate decreases with temperature, can be particularly well observed using a JSR. This is demonstrated in Figure 2 for the case of $n$-heptane under stoichiometric conditions [24]. This figure clearly shows a first temperature range (500-620 K) where reactivity increases with temperature. The NTC temperature zone can then be observed between 620 and $780 \mathrm{~K}$. Finally in a third area, reactivity again increases with temperature. Figure 2 also illustrates that while no thermal phenomenon is expected in a JSR functioning under isothermal conditions, the area of NTC shown in Figure 2a corresponds in a large part to the temperature range in which cool flames are observed in a rapid compression machine (RCM) for the same fuel under similar conditions. This is clearly shown by the experimental results of Minetti et al. [3] for $n$-heptane under stoichiometric conditions (see Figure 2b). 

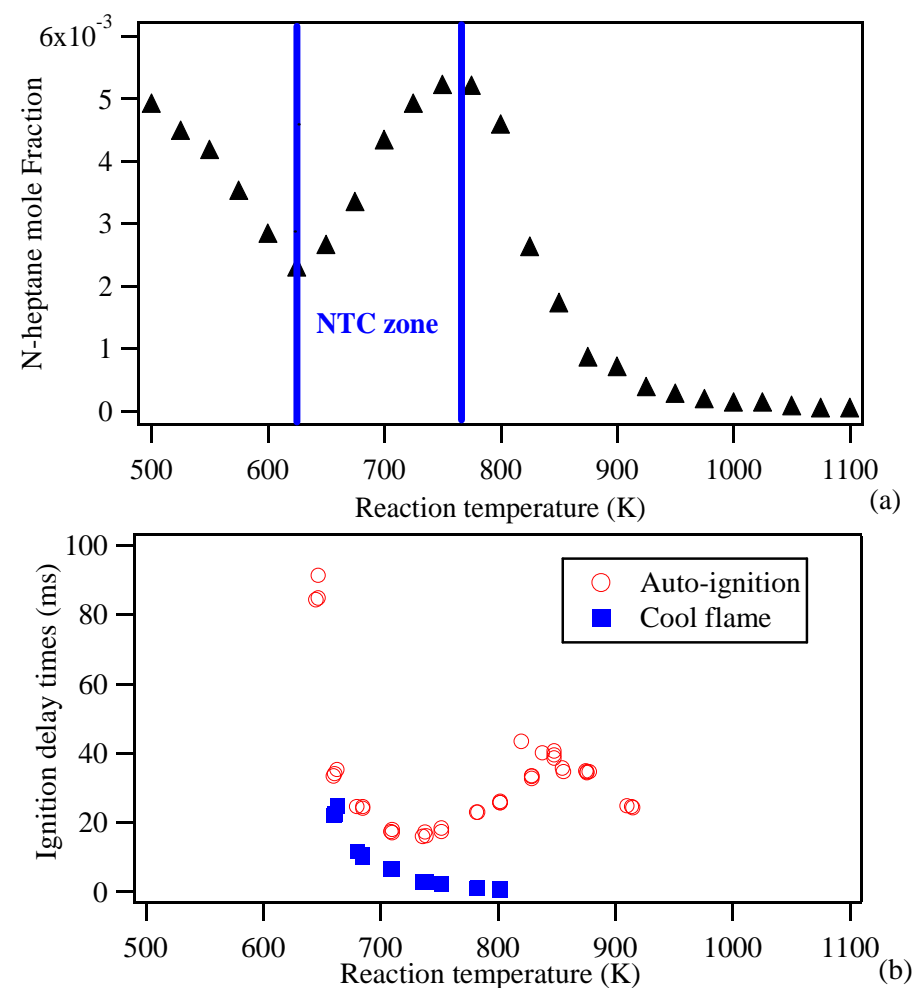

Figure 2. (a) Evolution of the $n$-heptane mole fraction during its JSR oxidation [24] showing the NTC zone; (b) ignition delay times of $n$-heptane in RCM [3] (stoichiometric mixtures in both cases, atmospheric pressure in JSR, pressure after compression from 3.7 to 4.6 bar (initial pressure of 162 Torr in RCM)).

Note that the temperature extent of the NTC may depend on pressure, fuel type, reactant composition, and other parameters. The temperature range shown in Figure 2 is not unique. For instance, the position of the NTC zone is shifted toward higher temperatures when the pressure increases due to the influence of pressure on the equilibrium of addition reactions to molecular oxygen. This explains why the cool flame area in the rapid compression machine at about 4 bar is shifted by approximately $20 \mathrm{~K}$ compared to the NTC zone in an atmospheric JSR.

As is also shown in Figure 1, reactions of ROO• radicals concurrent to hydroperoxide formation can lead to a wide range of products, such as alkenes, cyclic ethers, aldehydes, or ketones, which are commonly the major species observed during JSR low-temperature oxidation. The formation of cyclic ethers in the JSR can now be analyzed in great detail, as will be shown in the later part of this paper. New results have indicated that the formation of minor products such as carboxylic acids or species with two carbonyl functions can also occur, through a chemistry which is not yet fully elucidated, as is discussed later. 
When the temperature increases, enhanced reversibility of the addition to oxygen molecules makes the formation of ROO• radicals, and consequently of hydroperoxides less favored. Alkyl radicals then react with oxygen to yield large conjugated alkenes and $\bullet \mathrm{HO}_{2}$ radicals, or (if temperature is high enough) decompose giving small alkenes and alkyl radicals. $\bullet \mathrm{HO}_{2}$ radicals react mostly by a combination with themselves to give $\mathrm{H}_{2} \mathrm{O}_{2}$. Thus the reactions producing these radicals can almost be considered as termination steps. As the temperature increases still further, the decomposition of $\mathrm{H}_{2} \mathrm{O}_{2}$ starts, as a new degenerate branching chain reaction promoting a significant reactivity. While hydroperoxide formation triggers the start of autoignition, $\mathrm{H}_{2} \mathrm{O}_{2}$ production is of critical importance for the full development of ignition. A better knowledge of the formation of alkyl and hydrogen hydroperoxides and of the main radicals involved $\left(\bullet \mathrm{OH}\right.$ and $\left.\bullet \mathrm{HO}_{2}\right)$ is of great importance for a better mastering of autoignition. Later, this paper present the recent progress in this field.

Small aromatic compounds, such as benzene and toluene, have low-temperature oxidation behavior and a very different chemistry from the compounds described above. The differences are mainly due to the lack of easy isomerization of the peroxy radicals obtained from benzene and in the case of toluene to the unusual chemistry of the resonance-stabilized benzylic radical, which reacts mostly by radical terminations [25]. The low-temperature oxidation of benzene and toluene has been initiated through the presence of a more reactive coreactant, like an $n$-alkane (n-decane, where only $25 \%$ is added to the total fuel mole fraction) [23]. Under these conditions, the conversion of benzene remains extremely low at temperatures below $800 \mathrm{~K}$ and the main reaction product is phenol. This product comes mainly from the reaction between phenyl-peroxy $\left(\phi \mathrm{O}_{2} \bullet\right)$ and hydroperoxyl $\left(\mathrm{HO}_{2} \bullet\right)$ radicals (see Figure 3). The $\phi_{2} \bullet$ radical is formed from the phenyl radical, which arises from benzene by $\mathrm{H}$-atom abstractions by radicals generated due to the low-temperature oxidation of $n$-decane.

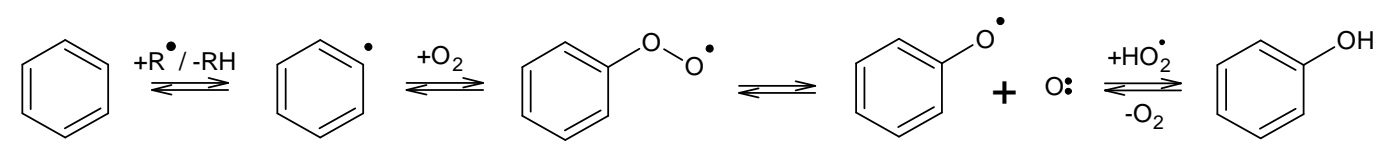

Figure 3. Formation of phenol during the low-temperature oxidation of benzene blended with $n$-decane [23].

Under the same conditions, toluene is significantly more reactive, with a conversion of $23 \%$ measured at $650 \mathrm{~K}$, and a well-marked NTC behavior between 700 and $800 \mathrm{~K}$. The main reaction product is benzaldehyde. Toluene is mainly consumed by $\mathrm{H}$-atom abstractions to yield benzylic radicals that react mainly by combining with $\mathrm{HO}_{2} \bullet$ radicals to form benzyl hydroperoxide (see Figure 4). This last species decomposes by the breakage of the fragile peroxy bond producing benzoxyl and HO• radicals. 
Benzoxyl radicals yield mainly benzaldehyde through the loss of an $\mathrm{H}$-atom and to a lesser extent benzene and $\bullet \mathrm{CHO}$ radicals.

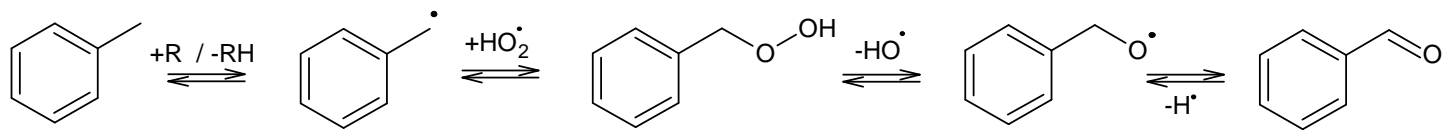

Figure 4. Formation of benzaldehyde during the low-temperature oxidation of toluene.

\section{Review of Recent Studies Using JSR to Study the Oxidation of Hydrocarbons and Oxygenated Molecules}

Well-stirred vessels, also called continuous-stirred tank reactors (CSTR), in which mixing was obtained by different methods, e.g., mechanical [26] or jet [27-31] stirring, were extensively used from the 1980s onward to study the oxidation of a wide range of fuels. In the 1980s, analytical studies involving detailed product formation measurements started to be published for gas-phase pyrolysis [31] and high-temperature (above $900 \mathrm{~K}$ ) oxidation of $\mathrm{C} 4+$ hydrocarbons (e.g., $n$-pentane [28], 1-butene [32], and even for that of some oxygenated compounds (e.g., furan, furfural) [33]. However, the work carried out at this time concerning low-temperature oxidation mainly addressed oscillatory reaction modes (periodic cool flames [26] or oscillatory single stage or multistage ignitions [26, 29] and plotted the location of the boundaries between the different reaction modes. Only limited data reported information on product formation [26, 30]. From the 1990s onward, a greater number of studies investigated this last aspect.

Since 1990, an increasing number of JSR experimental studies concerning detailed product formation during the low-temperature oxidation of $\mathrm{C}_{4+}$ hydrocarbons and oxygenated molecules have been published. A summary of these studies is given in Table 1, showing the range of temperatures, pressures, equivalence ratios $(\varphi)$, residence times $(\tau)$, and initial mole fractions $\left(x_{\text {fuel }}\right)$ analyzed. The considerable amount of results obtained at high temperatures $[19,21]$ are not in the scope of this paper, and only studies presenting results obtained below $750 \mathrm{~K}$ are shown. Note, however, that modeling has shown that the low-temperature reactions involving peroxy radicals can have a notable influence above $750 \mathrm{~K}$. For instance, the results obtained by Yahyaoui et al. [34] during the JSR study of 1-hexene oxidation from $750 \mathrm{~K}$ upward cannot be satisfactorily modeled over the lowest temperature range if low-temperature reactions are not considered [35]. 
Table 1. Summary of JSR Experimental Studies Carried Out after 1990 Concerning Product Formation during the Low-Temperature Oxidation of Hydrocarbons and Oxygenated Molecules. Only studies presenting experimental data obtained below $750 \mathrm{~K}$ are listed.

\begin{tabular}{|c|c|c|c|c|c|c|c|}
\hline Fuel & $T(K)$ & $P($ bar $)$ & $\tau$ & $x_{\text {fuel }}$ & $\varphi$ & Analytical Methoda $^{a}$ & Ref. \\
\hline \multicolumn{8}{|l|}{ Alkanes } \\
\hline$n$-Propane & $530-730$ & 1.067 & 6 & 0.12 & 1 & GC and SVUV-PIMS & [36] \\
\hline \multirow[t]{3}{*}{$n$-Butane } & $550-925$ & 1.067 & 6 & $2.3 \times 10^{-2}$ & 1 & $\mathrm{CW}-\mathrm{CRDS}$ and GC & {$[37,38]$} \\
\hline & $550-1000$ & 1.067 & 6 & $2.3 \times 10^{-2}$ & 1 & FAGE & [39] \\
\hline & $550-800$ & 1.067 & 6 & $4.0 \times 10^{-2}$ & 1 & GC and SVUV-PIMS & {$[40-42]$} \\
\hline$n$-Hexane & $500-850$ & 1.067 & 2 & $2.0 \times 10^{-2}$ & 1 & GC and SVUV-PIMS & {$[43]$} \\
\hline 2-Methyl-pentane & $500-825$ & 1.067 & 2 & $2.0 \times 10^{-2}$ & 1 & GC and SVUV-PIMS & \\
\hline 3-Methyl-pentane & $500-825$ & 1.067 & 2 & $2.0 \times 10^{-2}$ & 1 & GC and SVUV-PIMS & \\
\hline 2,2-Dimethyl-butane & $500-1075$ & 1.067 & 2 & $2.0 \times 10^{-2}$ & 1 & GC and SVUV-PIMS & \\
\hline 2,3-Dimethyl-butane & $500-1000$ & 1.067 & 2 & $2.0 \times 10^{-2}$ & 1 & GC and SVUV-PIMS & \\
\hline \multirow[t]{3}{*}{$n$-Heptane } & $550-1150$ & $1.013-40.52$ & $0.1-2$ & $5.10^{-4}$ to $10^{-3}$ & 1 & $\mathrm{GC}$ & {$[44,45]$} \\
\hline & $500-1100$ & 1.067 & 2 & $5.0 \times 10^{-3}$ & 1 & GC and SVUV-PIMS & {$[24]$} \\
\hline & $500-700$ & 2 & 0.4 & $n a^{b}$ & $n a^{b}$ & GC & {$[46]$} \\
\hline$n$-Heptane + iso-octane & $550-1150$ & 10.13 & 1 & $10^{-3}$ & 1 & GC & {$[47]$} \\
\hline \multirow[t]{2}{*}{ iso-Octane } & $550-1150$ & 10.13 & $0.1-2$ & $5.10^{-4}$ to $10^{-3}$ & $0.3-1.5$ & $\mathrm{GC}$ & {$[44]$} \\
\hline & $600-700$ & $7 \& 9$ & 0.4 & $n a^{b}$ & 1 & GC & [48] \\
\hline$n$-Octane & $500-1100$ & 1.067 & 2 & $5.0 \times 10^{-3}$ & $0.25,1 \& 2$ & $\mathrm{GC}$ & [49] \\
\hline 2-Methyl-heptane & $500-1200$ & 10.13 & 0.7 & $10^{-3}$ & $0.5,1 \& 2$ & GC and FTIR & {$[50]$} \\
\hline 3-Methyl-heptane & $530-1220$ & 10.13 & 0.7 & $10^{-3}$ & $0.5,1 \& 2$ & GC and FTIR & {$[51]$} \\
\hline 2,5-Dimethyl-hexane & $500-1200$ & 10.13 & 0.7 & $10^{-3}$ & $0.5,1 \& 2$ & GC and FTIR & {$[52]$} \\
\hline \multirow[t]{4}{*}{$n$-Decane } & $550-1150$ & 10.13 & $0.5-1$ & $10^{-3}$ & $0.1-1.5$ & GC & {$[53]$} \\
\hline & $550-1100$ & 1.013 & 1.5 & $2.3 \times 10^{-3}$ & 1 & $\mathrm{GC}$ & {$[54]$} \\
\hline & $550-1100$ & 1.067 & 1.5 & $2.3 \times 10^{-3}$ & 1 & GC & {$[14]$} \\
\hline & $550-1100$ & 1.067 & 2 & $2.5 \times 10^{-3}$ & 0.41 & $\mathrm{GC}$ & [23] \\
\hline$n$-Tetradecane & $500-700$ & 2 & 0.4 & $n a^{b}$ & $n a^{b}$ & $\mathrm{GC}$ & {$[46]$} \\
\hline \multirow[t]{2}{*}{$n$-Hexadecane (+ $n$-decane) } & $550-1100$ & 1.013 & 1.5 & $\begin{array}{c}8.1 \times 10^{-4}(1.50 \times \\
\left.10^{-3}\right)\end{array}$ & 1 & GC & {$[54]$} \\
\hline & $550-1100$ & 1.067 & 1.5 & $\begin{array}{c}5.2 \times 10^{-4}(1.48 \times \\
\left.10^{-3}\right)\end{array}$ & 1 & GC & {$[14]$} \\
\hline \multicolumn{8}{|l|}{ Naphthenes } \\
\hline Cyclohexane & $500-1100$ & 1.067 & 2 & $6.67 \times 10^{-3}$ & $0.5,1 \& 2$ & GC & {$[55]$} \\
\hline Ethyl-cyclohexane & $500-1100$ & 1.067 & 2 & $5.0 \times 10^{-3}$ & $0.25,1 \& 2$ & GC & [49] \\
\hline n-Butyl-cyclohexane & $500-1100$ & 1.067 & 2 & $4.0 \times 10^{-3}$ & $0.25,1 \& 2$ & $\mathrm{GC}$ & {$[56]$} \\
\hline \multicolumn{8}{|l|}{ Alkenes } \\
\hline 1-Hexene & $500-1100$ & 1.067 & 2 & $10^{-2}$ to $2 \times 10^{-2}$ & 1 & GC and SVUV-PIMS & {$[22]$} \\
\hline 2-Hexene & $500-1100$ & 1.067 & 2 & $10^{-2}$ to $2 \times 10^{-2}$ & 1 & $\mathrm{GC}$ & \\
\hline 3-Hexene & $500-1100$ & 1.067 & 2 & $10^{-2}$ to $2 \times 10^{-2}$ & 1 & GC & \\
\hline 1-Octene & $500-1100$ & 1.067 & 2 & $5.0 \times 10^{-3}$ & $0.25,1 \& 2$ & $\mathrm{GC}$ & [49] \\
\hline \multicolumn{8}{|l|}{ Aromatics } \\
\hline Benzene (+ $n$-decane) & $550-1100$ & 1.067 & 2 & $\begin{array}{c}7.5 \times 10^{-3}(2.5 \times \\
\left.10^{-3}\right)\end{array}$ & 1 & GC & {$[23]$} \\
\hline Toluene (+ $n$-decane) & $550-1100$ & 1.067 & 2 & $7.5 \times 10^{-3}\left(2.5 \times 10^{-3}\right)$ & 1 & $\mathrm{GC}$ & \\
\hline$n$-Butyl-benzene & $550-1100$ & 1.067 & 2 & $4.0 \times 10^{-3}$ & $0.25,1 \& 2$ & GC & {$[57]$} \\
\hline$n$-Hexyl-benzene & $550-1100$ & 1.067 & 2 & $3.33 \times 10^{-3}$ & 1 & GC & {$[17]$} \\
\hline \multicolumn{8}{|l|}{ Methyl esters } \\
\hline Methyl hexanoate & $500-1000$ & 10.13 & 1.5 & $10^{-3}$ & $0.5-1.5$ & GC and FTIR & {$[58]$} \\
\hline trans-Methyl-3-hexenoate & $560-1220$ & 10.13 & 0.7 & $10^{-3}$ & $0.6,1 \& 2$ & GC and FTIR & [59] \\
\hline Methyl heptanoate & $550-1150$ & 10.13 & 0.7 & $10^{-3}$ & $0.6-2$ & GC and FTIR & {$[60]$} \\
\hline Methyl decanoate & $500-1100$ & 1.067 & 1.5 & $2.1 \times 10^{-3}$ & 1 & $\mathrm{GC}$ & [61] \\
\hline
\end{tabular}




\begin{tabular}{|c|c|c|c|c|c|c|c|}
\hline Fuel & $T(K)$ & $P($ bar $)$ & $\tau$ & $x_{\text {fuel }}$ & $\varphi$ & Analytical Method ${ }^{a}$ & Ref. \\
\hline Methyl palmitate (+ $n$-decane) & $550-1100$ & 1.067 & 1.5 & $\begin{array}{c}5.2 \times 10^{-4}(1.48 \times \\
\left.10^{-3}\right)\end{array}$ & 1 & GC & [14] \\
\hline Methyl oleate (+ $n$-decane) & $550-1100$ & 1.067 & 1.5 & $\begin{array}{c}5.2 \times 10^{-4}(1.48 \times \\
\left.10^{-3}\right)\end{array}$ & 1 & GC & [15] \\
\hline \multicolumn{8}{|l|}{ Acohols } \\
\hline \multirow[t]{2}{*}{ iso-Pentanol } & $530-1220$ & 10.13 & 1 & $10^{-3}$ to $2 \times 10^{-3}$ & $0.2-2.5$ & GC and FTIR & [62] \\
\hline & $700-1200$ & 5 & $0.35-0.7$ & $10^{-3}$ & $0.35-4$ & GC and FTIR & [63] \\
\hline$n$-Hexanol & $560-1220$ & 10.13 & 0.7 & $10^{-3}$ & $0.5-3.5$ & GC and FTIR & [64] \\
\hline \multicolumn{8}{|c|}{ Ethers } \\
\hline \multirow[t]{2}{*}{ Dimethyl ether } & $550-1275$ & $1.01-10.13$ & 1 & $10^{-3}$ to $2 \times 10^{-3}$ & $0.2-2.5$ & GC & {$[65,66]$} \\
\hline & $n a^{b}$ & $n a^{b}$ & $n a^{b}$ & $n a^{b}$ & $n a^{b}$ & $n a^{b}$ & {$[67]$} \\
\hline $\begin{array}{l}\text { Methyl-tert-butyl-ether } \\
\text { (+n-heptane) }\end{array}$ & $580-1050$ & 10.13 & 0.5 & $5 \times 10^{-4}\left(5 \times 10^{-4}\right)$ & 1 & GC & [68] \\
\hline $\begin{array}{l}\text { Ethyl-tert-butyl-ether } \\
\text { (+n-heptane) }\end{array}$ & $580-1050$ & 10.13 & 0.5 & $5 \times 10^{-4}\left(5 \times 10^{-4}\right)$ & 1 & GC & \\
\hline \multicolumn{8}{|c|}{ Aldehydes } \\
\hline$n$ - and iso-butanal & $540-1100$ & 10.13 & 0.7 & $1.5 \times 10^{-3}$ & $0.3-1.5$ & GC and FTIR & [69] \\
\hline
\end{tabular}

${ }^{a} \mathrm{GC}$ : gas chromatography; SVUV-PIMS: synchrotron vacuum ultra violet photo-ionization mass spectrometry; cw-CRDS: continuous-wave cavity ring-down spectroscopy; FAGE: fluorescence assay with gas expansion; FTIR: Fourier transform infrared spectroscopy.

${ }^{b}$ na: Information not available.

The first team that used JSR to study product formation during the low-temperature oxidation of large alkanes was that of D'Anna and co-workers in 1992 [48]. These authors employed a metallic reactor, whereas the reactors currently in use are of fused silica. However like the more recent reactors, that of D'Anna et al. was based on the design of David and Matras [70]. This reactor geometry originated from the earlier work of Matras and Villermaux [71] (1973, paper in French). The reactor was not operated under isothermal conditions and, as mentioned in the beginning of this part of the current paper, different dynamic behaviors could arise (e.g., cool flames, high-temperature ignitions). Permanent oscillations due to cool flames for several minutes have been reported [72]. These authors studied $n$-heptane [46], iso-octane [48], and $n$-tetradecane [46] and reported the formation of different oxygenated products, including several cyclic ethers, ketones, and aldehydes. The only attempt to model these results concerned dynamic behaviors [72]. Similar experiments have recently been performed by Stoehr and Peters in the case of dimethyl ether, using a fused silica JSR [67].

Shortly after the work of the team of Napoli, in line with their work on high-temperature oxidation, e.g., $[27,32]$, the team of Orléans started to use a fused silica JSR, also based on the design of David and Matras [70], to study the low-temperature oxidation of $n$-heptane [44,45] from 1 to 40 bar under isothermal conditions. More details about this JSR can be found in $[7,73]$. The isothermicity was ensured by using a very high dilution factor (fuel mole fraction of $0.1 \%$ ). These milestone results describe a wide range of products analyzed by gas chromatography, including the quantification of three cyclic ethers (substituted furans). These results have since been used as validation targets by 
numerous modelers $[10,12]$. The team of Dagaut produced a few more data on iso-octane, $n$-decane, and ethers (methyl-tert-butyl-ether and ethyl-tert-butyl-ether) in mixtures with $n$-heptane in the mid-1990s. Afterward, they studied a wide range of compounds at higher temperatures, with no more low-temperature hydrocarbon oxidation studies until they published three of them on methyl-heptanes [50,51] and 2,5-dimethylhexane [52] from 2011. On 2008, this group started to study the low-temperature oxidation at 10.13 bar of oxygenated compounds, such as methyl esters [58-60], alcohols [62-64], and even aldehydes [69] that are formed during the oxidation of alcohols and among which $n$-butanal displays a significant low-temperature reactivity.

As is shown in Table 1, since 2008, the team of Battin-Leclerc in Nancy has been studying the lowtemperature oxidation of a wide range of $C_{3}$ to $C_{16}$ hydrocarbons and $C_{4}$ to $C_{18}$ methyl esters in an atmospheric pressure JSR. The Nancy team has a long experience in JSR studies of pyrolysis $[31,74,75]$ and high-temperature oxidation [25]. The fused silica JSR they use, which is also based on the design of David and Matras [70], was described in detail by Herbinet and Dayma [7]. The mixing of the gas phase is achieved using turbulent jets obtained from nozzles located on an injection cross (see Figure 5). The use of atmospheric pressure rather than of higher pressures as in the work of Dagaut et al. does not lead to significant differences in product formation for the reactants studied by the two teams (see Table 1).



Figure 5. Photograph of the fused silica JSR used by the Nancy team showing the injection cross and the outlet tube.

As is shown in Table 1, the initial reactant mole fractions used by the team of Battin-Leclerc (from $2 \times$ $10^{-3}$ to 0.12 ) were always larger than those used by the team of Dagaut (from $5 \times 10^{-4}$ to $2 \times 10^{-3}$ ). Nevertheless the conditions used by the team of Battin-Leclerc can still be considered as isothermal, with temperature gradients in the reactor below $5 \mathrm{~K}$. These large initial reactant mole fractions have allowed the Nancy team to detect a wider range of products than described in the literature, as will be detailed in the later part of this paper. The families of hydrocarbons studied are linear, branched, and 
cyclic alkanes, linear alkenes, aromatics and linear methyl esters. For alkanes (see chemistry described in the Generalities about Low-Temperature Oxidation section) and alkenes (for more details about alkenes chemistry, see $[19,22])$, great care has been taken to increase the range of products analyzed, as detailed in the following parts of this paper. For aromatics, in addition to small aromatics [23], Battin-Leclerc et al. have studied $n$-butylbenzene [57] and $n$-hexylbenzene [17], which have a very similar low-temperature reactivity to that of $n$-alkanes. These compounds can be considered to be $n$-alkanes attached to a nonreactive superatom: the phenyl ring, with some specificities due to the presence of labile benzylic $\mathrm{H}$-atoms [17].

The quality of the above-mentioned experimental results depends on the ideality of the reactor used. If the criteria for the design of such reactors proposed by David and Matra [70] are respected, a perfect macromixing inside the reactor should be obtained. This has been checked using residence distribution studies at atmospheric pressure [71] and at 10 atm [73]. Note, however, that no work on this topic has been performed since 1986, and new work with up-to-date experimental techniques could bring valuable information to the subject. For isothermal studies, thermal homogeneity is also of great importance. As was shown in 1979 by Azay and Côme [74], in the case of gas-phase pyrolysis, sufficient preheating of the gases can eliminate temperature gradients. For exothermic reactions such as oxidations, a high level of dilution is also required. In Nancy, the reactor is preceded by an annular preheating zone in which the gas temperature is increased to the reactor temperature before it enters inside the vessel. The residence time of the mixture inside the annular preheater is very short compared to that in the reactor (a few percent only).

Other potential sources of uncertainties can be probing problems and wall effects. When probing major stable products, no particular problem has been encountered. However, difficulties met when probing minor species are described further on in this text. Wall effects are rarely reported because they prevent a good reproducibility of the results, but they can be a significant problem with this kind of reactor [31]. Except in the recent study of Herbinet et al. [42] described further on in the text, wall reactions are generally considered as negligible during hydrocarbon oxidation. In the case of oxygenated species, wall reactions can have a more significant influence, as has been shown in the case of ethers [76].

The accuracy of JSR measurements is mainly determined by the accuracies in the temperature and flow measurements and analytical methods. Temperatures inside a JSR are mostly measured by a type $K$ thermocouple located at the center of the injection cross [7]. Accuracy on these thermocouple measurements are around $\pm 2 \mathrm{~K}$. Gas and liquid flows are currently mostly regulated by mass flow 
controllers with an error of about $0.5 \%$ for each flow channel. Errors in gas chromatography measurements are usually $5 \%$ for hydrocarbons and $10 \%$ for most oxygenated species.

\section{Knowledge Gained from Studies Using Gas Chromatography Analyses}

Recent studies focused on the identification of typical reaction products that are formed during the low-temperature oxidation of organic compounds. As presented earlier in this paper, the chemistry involved in the low-temperature oxidation of organic compounds is complex. It involves several propagation steps to form more or less stable molecules such as olefins, cyclic ethers, aldehydes, or ketones. These can be analyzed using gas chromatography (GC). This method has the advantage that it facilitates the separation of isomers thanks to the use of appropriate chromatographic columns. Peroxides, which are fragile because of the weak peroxy bond, cannot be analyzed by gas chromatography and other analytical methods have to be used for their study (see later parts of this paper). This section focuses on progress in understanding the low-temperature oxidation of organic compounds that has been made with the help of GC by analyzing the gases directly as they leave the reactor via a heated transfer line.

\section{Identification and Quantification of Cyclic Ethers}

Alkenes, ketones and aldehydes, and cyclic ethers with the same skeleton as the reactant are all typical reaction products formed during the low-temperature oxidation of organic compounds, especially $n$-alkanes (see Figure 1). We concentrate here on the formation of cyclic ethers for which recent progress related to identification and quantification has been made from JSR studies. The presence of cyclic ethers has been reported in a number of $n$-alkanes JSR studies listed in Table 1. During their pioneer study of the low-temperature oxidation of $n$-heptane [45] and $n$-decane [53], Dagaut et al. observed the formation of several five-membered ring cyclic ether isomers (tetrahydrofurans or oxolanes). More recently, not only oxolanes but also oxiranes, oxetanes, and tetrahydropyrans have been observed upon low-temperature oxidation of propane, $n$-butane [42], hexane isomers [43], $n$-heptane [24], $n$-decane [14], and $n$-hexadecane [14]. Cyclic ether formation was also observed with other types of fuels: naphthenes [49,55], olefins [22], and esters $[14,15,61]$.

The chemistry involved in the formation of cyclic ethers is complex, but is relatively well known [18]. The steps involved in the formation of 2-ethyl-tetrahydrofuran from the $n$-hexyl radical formed during the low-temperature oxidation of $n$-hexane are shown in Figure 6 . The first step is the addition of the $n$-hexyl radical to an oxygen molecule (reaction (1)) to form a hexylperoxy radical (ROO•). Then, the 
ROO• radical undergoes an isomerization reaction (2) to yield hexylhydroperoxy radicals $(\bullet 0 O O H)$. Several isomerizations are possible according to the number of atoms in the cyclic transition state. Only isomerizations through five-, six-, seven-, and eight-membered cyclic transition states are considered in detailed kinetic models [19]. Third, $\bullet$ QOOH radicals can decompose to yield cyclic ethers and $\bullet \mathrm{OH}$ radicals (3). The number of atoms in the cycle depends on the relative position of both the radical center and the hydroperoxy function in the $\bullet \mathrm{QOOH}$ radical. Thus, as already demonstrated from experiments in static reactors, e.g., by the team of Walker [77], cyclic ethers formed upon the low-temperature oxidation of alkanes are oxiranes, oxetanes, oxolanes, and tetrahydropyrans (with possible cis and trans isomers if the cyclic ether contains two alkyl side chains on different carbon atoms). While a direct measurement can only be found in the literature for the formation of a fourmembered ring (oxetane) during the oxidation of neo-pentane added to slowly reacting mixtures of $\mathrm{H}_{2}$ $+\mathrm{O}_{2}$ [78], a large effort to calculate the related rate parameters has recently been undertaken by several team using quantum mechanics methods [79-83]. This last approach is of great value to replace the previous estimates of rate constant by approximations and correlations [19]. Nevertheless, although the chemical pathway leading to cyclic ethers is now well accepted, significant deviations in the rate parameters involved remain [83] and progress is still needed to accurately predict the distribution of these species [24].

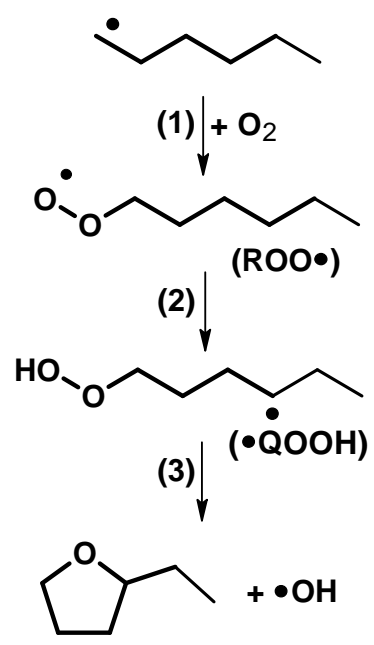

Figure 6. Formation of 2-ethyl-tetrahydrofuran from the $n$-hexyl radical upon low-temperature oxidation of $n$-hexane.

Many cyclic ethers are formed during the low-temperature oxidation of organic compounds, all these species being isomers. This makes their identification difficult because of their close retention times in GC analyses. In addition, their mass spectra (using electronic impact at $70 \mathrm{eV}$ ) are often not included in the databases. As an example, Hakka et al. [14] observed the formation of $16 \mathrm{C}_{10} \mathrm{H}_{20} \mathrm{O}$ cyclic ethers 
(some of which were present twice in GC analyses because of cis/trans isomerizations) during the low-temperature oxidation of $n$-decane. All the related peaks in the chromatogram were included in a 4 min retention time window.

Herbinet et al. [84] studied the low-temperature oxidation of $n$-alkanes from $n$-pentane to $n$-hexadecane at $650 \mathrm{~K}$ with attention being paid to the formation of different types of cyclic ethers. This study allowed the existing set of mass spectra concerning cyclic ethers to be completed and rules for the fragmentation of these species in electronic impact mass spectrometry to be derived. These rules were useful for the identification of cyclic ethers formed during the low-temperature oxidation of fuels having more complex structure than $n$-alkanes, such as methyl esters (methyl decanoate [61] and methyl palmitate [14], branched isomers of hexane [43], hexene isomers [22], and ethylcyclohexane [49].

As far as large $n$-alkanes (from $C_{6}$ ) are concerned $[14,24,43]$, it was observed that oxolanes are the most abundant cyclic ethers. Oxiranes and tetrahydropyrans are formed in lower amounts, with oxetanes at intermediate mole fractions, as illustrated in Figure 7 for $n$-heptane. This probably explains why oxolanes were the only cyclic ethers detected by Dagaut et al. $[45,53]$.
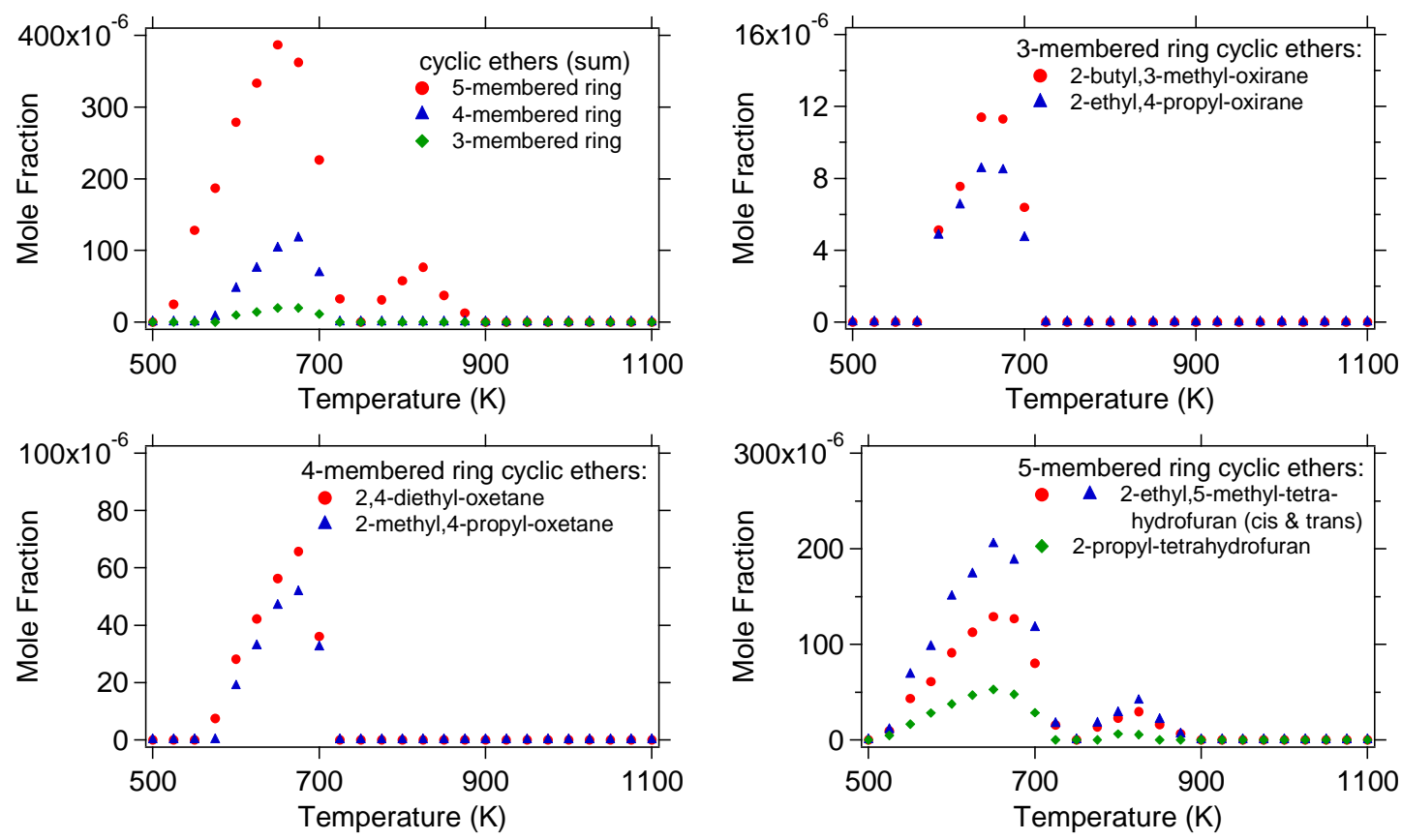

Figure 7. Evolution with temperature of the mole fractions of cyclic ethers formed during the JSR oxidation of $n$-heptane [24] ( $P=1 \mathrm{~atm}, \varphi=1, \tau=2 \mathrm{~s}$, inlet mole fraction $=0.005)$. 
In the case of $n$-butane, tetrahydrofuran was present in small amounts because its formation can only be derived from the abstraction of primary $\mathrm{H}$-atoms [42]. Taatjes et al. studied the reactions of butyl radicals with oxygen taking advantage of chlorine laser-photolysis to initiate the low-temperature oxidation of $n$-butane [85] or iso-butane [86] in a flow tube with photoionization mass spectrometry as an analytical method. In the case of $n$-butane, through the clever use of deuterated species, these authors obtained cyclic ether branching ratios. These results show a selectivity of cyclic ethers mostly similar to that observed by Herbinet et al. [42]. The selectivity at $650 \mathrm{~K}$ for oxetane and oxolane is close to 0.12 and 0.04 , respectively, in both cases. Nevertheless, the selectivity of 2,3-dimethyl-oxirane is significantly larger in JSR experiments [42] than in the flow tube ones [85] ( 0.28 instead of 0.05 at 650 K). Note that the same oxygenated species selectivities as [42] were obtained with another initial fuel mole fraction [38] and that a model with rate coefficients revised from theoretical calculations well predicts oxiranes as having the largest selectivity among the cyclic ethers formed from $n$-butane oxidation in a JSR [83].

Specificities in the formation of cyclic ethers were observed for other fuel types due to their structures. As an example, Wang et al. [43] observed the formation of numerous cyclic ethers from the oxidation of methyl-pentanes and dimethyl-butanes. Their structures differ from those of cyclic ethers formed from $n$-alkanes by the position of the alkyl side chains that are not necessarily on the two carbon atoms linked to the oxygen one. They also observed a favored formation of cyclic ethers from branched reactants.

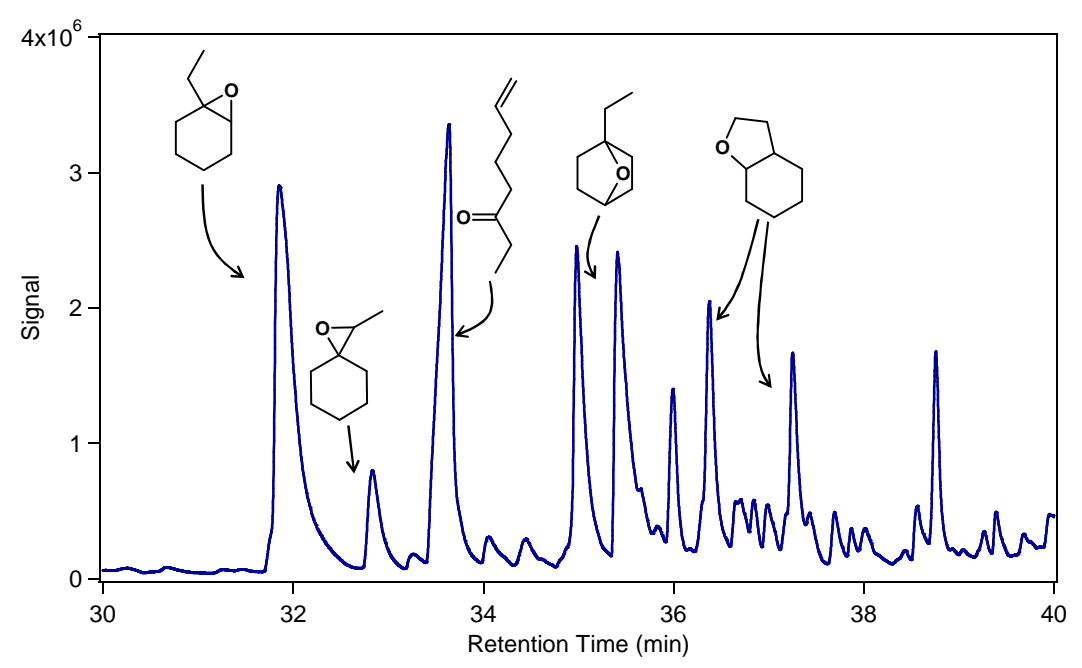

Figure 8. Example of a chromatogram obtained using mass spectrometry detection showing the cyclic ethers formed during the JSR oxidation of ethyl-cyclohexane [49] ( $T=630 \mathrm{~K}, P=1 \mathrm{~atm}, \varphi=1, \tau=2 \mathrm{~s}$, fuel inlet mole fraction $=0.005$ ). 
As far as naphthenic compounds are concerned, bicyclic ethers are observed except those corresponding to oxetanes (four-membered ring ethers) because this type of species is unstable and opens through a concerted mechanism to yield unsaturated ketones $[49,55]$. This is illustrated in Figure 8, which shows the cyclic ethers and unsaturated ketone (oct-7-en-3-one) formed from ethylcyclohexane [49].

Apart from oxiranes, which can easily be formed by the addition of $\mathrm{HO}_{2} \bullet$ radicals to the double bond, only five-membered ring cyclic ethers were observed during the oxidation of hexene isomers [22]: cis and trans 2-methyl-5-hydroxymethyl-tetrahydrofurans (from 1-hexene only), cis and trans 2,5-dimethyl-tetrahydrofurans (from 1- and 2-hexenes), and dimethyl-dihydrofuran (from the three isomers). The structures of these ethers are displayed in Figure 9. The formation of 2-methyl-5hydroxymethyl-tetrahydrofuran and 2,5-dimethyl-tetrahydrofuran isomers was proposed [22] to be from radicals obtained by the addition of $\bullet \mathrm{OH}$ radicals and $\mathrm{H}$-atoms, respectively, to the double bond of fuel molecules. The formation of dimethyl-dihydrofuran is explained by reactions of radicals obtained by $\mathrm{H}$-atom abstraction from fuel molecules.

2-methyl,5-hydroxymethyl-tetrahydrofuran



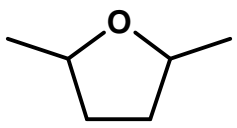

2,5-dimethyl-dihydrofuran

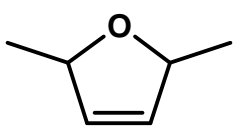

2,5-dimethyl-tetrahydrofuran

Figure 9. Structures of five-membered ring cyclic ethers observed during the low-temperature oxidation of hexene isomers in an atmospheric JSR ( $T=500-900 \mathrm{~K}, P=1 \mathrm{~atm}, \varphi=1, \tau=2 \mathrm{~s}$, inlet mole fraction $=0.01)[22]$.

\section{Formation of Species with Two Carbonyl Groups and of Carboxylic Acids}

The formation of species with two carbonyl functions (diones) has been observed by GC analyses during low-temperature oxidation of some $n$-alkanes [24,43]. As an example, 2,4-hexadione was detected during the low-temperature oxidation of $n$-hexane [43] and 2,4- and 3,5-heptadiones were discerned during the low-temperature oxidation of $n$-heptane[24]. Figure 10 displays the mole fraction profile of 2,4-hexadione obtained during the low-temperature oxidation of $n$-hexane. The shape of this profile is very similar to that of species such as cyclic ethers. 


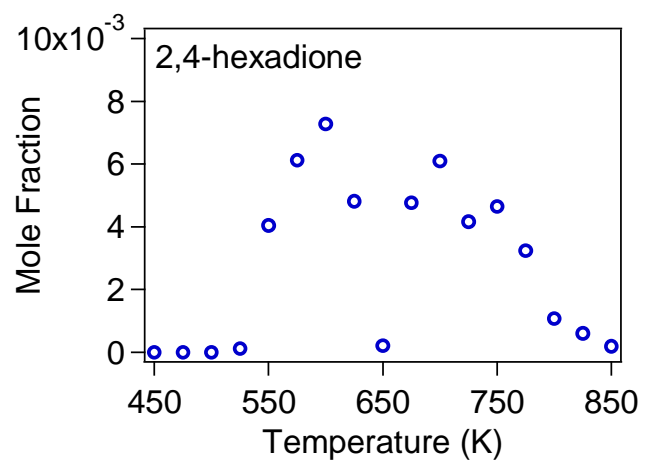

Figure 10. Mole fraction profile for the 2,4-hexadione formed during the low-temperature oxidation of $n$-hexane in a JSR [43] ( $P=1 \mathrm{~atm}, \varphi=1, \tau=2 \mathrm{~s}$, inlet mole fraction $=0.02 \%)$.

As is shown in Figure 11, diones observed during the low-temperature oxidation of $n$-hexane and $n$-heptane all have two carbonyl groups in positions $n$ and $n+2$. No species with an aldehyde group was seen. This observation led to the conclusion that diones are most likely formed from ketohydroperoxides since the most abundant ones (according to model predictions) are those with the two groups in positions $\mathrm{n}$ and $\mathrm{n}+2$, which are formed through two isomerizations each involving a six-membered ring transition state. The abundance of these ketohydroperoxides is explained by the fact that the $\bullet \mathrm{QOOH}$ radicals involved are those that are also the source of oxetanes. The formation of oxetanes [19] is significantly less favored than that of oxolanes, which are formed from $\bullet$ QOOH radicals that are easily obtained from ROO• radicals isomerization via a seven-membered ring transition state.<smiles>CCC(=O)CC(C)=O</smiles>

2,4-hexadione<smiles>CCCC(=O)CC(C)=O</smiles>

2,4-heptadione<smiles>CCC(=O)CC(=O)CC</smiles>

3,5-heptadione

Figure 11. Structures of the diones observed during the low-temperature oxidation of $n$-hexane [43] and $n$-heptane [24].

The formation of species with two carbonyl groups was not observed by GC analysis during the low-temperature oxidation of propane [36], $n$-butane [42], naphthenes [49,55,56], and olefins [22]. This was probably due to the short chain length of small $n$-alkanes or to the presence of cyclic structures and double bonds in naphthenes and olefins, respectively, which hinder isomerization and subsequent formation of ketohydroperoxides.

The formation of carboxylic acid has only rarely been reported during low-temperature oxidation studies. However, the formation of acetic and propanoic acids was recently described in several GC 
works $[24,36,42]$ of linear $C_{3}-C_{7}$ alkanes. The $G C$ mole fraction profile of acetic acid obtained in the low-temperature oxidation study of $n$-butane in a JSR are displayed in Figure 12 . This profile is in good agreement with that obtained by mass spectrometry (this technique is described in the coming part). It has been shown that in addition to sulfuric and nitric acids, carboxylic acids (especially formic and acetic acids) can contribute to the acidity of gas and aqueous phases of the atmosphere in urban and in remote regions [87]. As will be discussed at the end of the next section, comparisons with mole fraction profiles obtained using mass spectrometry have shown that GC quantification of diones and acids can be subject to large uncertainties.

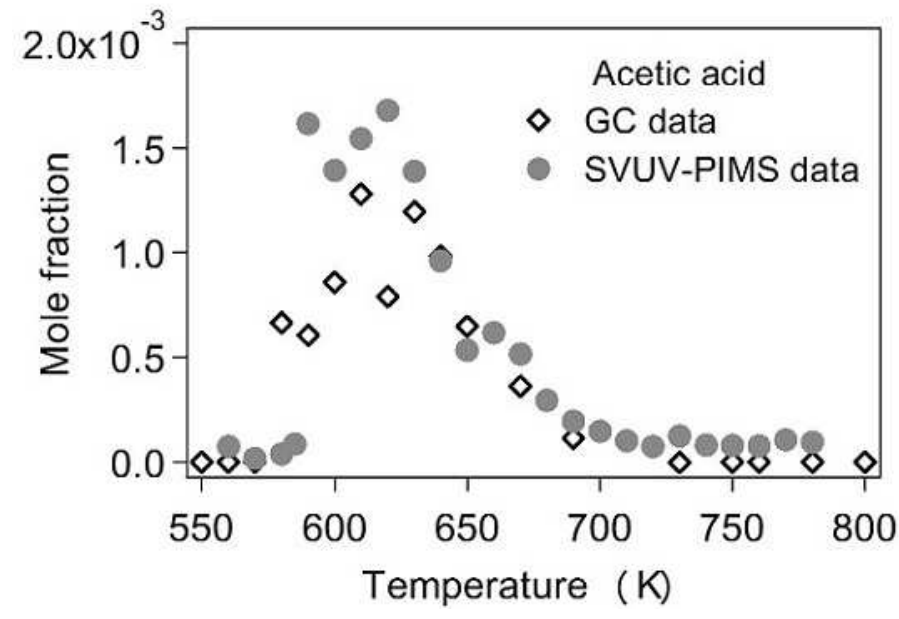

Figure 12. GC and SVUV-PIMS mole fraction profiles of acetic acid obtained during the oxidation of propane in a JSR [42].

\section{Knowledge gained from Studies Using Mass Spectrometry Analysis}

Mass spectrometry (MS) has proven a powerful tool to probe combustion species, especially in flames [88]. The strength of this tool is further increased when a synchrotron vacuum ultraviolet (SVUV) photoionization (PI) mass spectrometer is used, as is shown by the review of Qi [89], or by the paper of Taatjes et al. [90], which demonstrated for the first time enol detection in a flame. The first coupling of a SVUV-PI mass spectrometer to a JSR was made by Battin-Leclerc et al. [40] in 2010, using molecular-beam sampling. As is shown in Figure 13, the coupling to the reactor, which was located in an oven, was made through a quartz cone-like nozzle inserted on the side of the reactor. The tip of the cone was pierced with a $75-\mu \mathrm{m}$ orifice. 


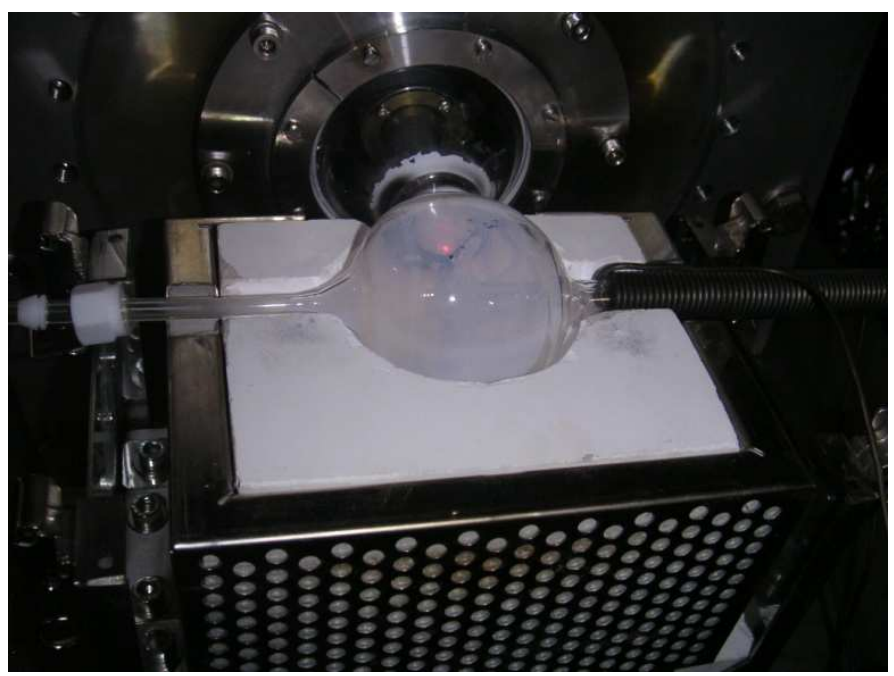

Figure 13. Photograph of a JSR coupled to the SVUV photoionization mass spectrometer [42].

\section{Analysis of Hydroperoxides}

Different types of hydroperoxides have been detected depending on the fuel studied:

- alkylhydroperoxides of the same size as the reactant for propane and $n$-butane,

- smaller alkylhydroperoxides than the reactant for $n$-butane (in this case only $\mathrm{CH}_{3} \mathrm{OOH}$ and $\mathrm{C}_{2} \mathrm{H}_{5} \mathrm{OOH}$ were detected),

- ketohydroperoxides of the same size as the reactant for $n$-butane, all isomers of hexane that were reactive under the conditions studied (i.e., $n$-hexane, 2-methylpentane, 3-methylpentane, 2,2-dimethylbutane) and $n$-heptane,

- alkenylhydroperoxides of the same size as the reactant deriving from the resonance stabilized radicals for 1-hexene.

Figure 14a presents the photoionization efficiency spectra for the four hydroperoxide species detected during $n$-butane oxidation; i.e., methylhydroperoxide at $m / z \quad 48$, ethyl hydroperoxide at $m / z 62$, butylhydroperoxides at $m / z 90$, and butylketohydroperoxides at $m / z 104$, with several isomers possible for the last two compounds. Concerning ketohydroperoxides, Eskola et al. [85] obtained a very similar photoionization efficiency spectrum at $m / z 104$ to that of Figure 14 in their study of $n$-butane oxidation using SVUV-PIMS at the Berkeley Advanced Light Source. Figure 14b shows the very specific shape of the temperature evolution of the signal obtained for hydroperoxides, with a very sharp peak below $600 \mathrm{~K}$. This shape is very different to that obtained for other products, as is seen from Figures 7 and 10 for cyclic ethers and diones, respectively. 




a)

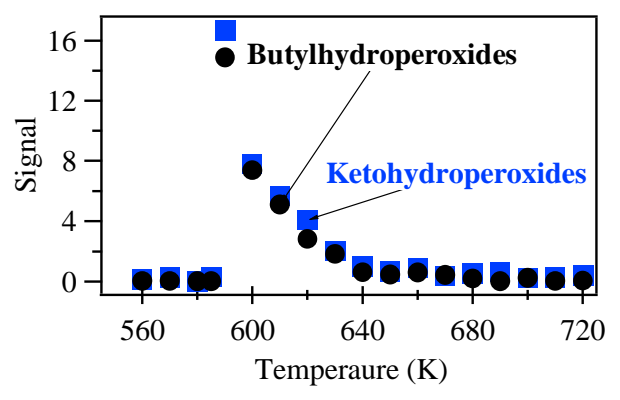

b)

Figure 14. SVUV-PIMS analysis of the JSR oxidation of $n$-butane [40-42]. (a) Photoionization efficiency spectra (in arbitrary units) of masses corresponding to hydroperoxides $(m / z=48,62,90,104), \mathrm{C}_{4} \mathrm{H}_{8} \mathrm{O}$ compounds $(m / z=72)$, diones $(m / z=86)$, and species with a carbonyl and an alcohol function $(m / z=$ 88), sampled at a reactor temperature of $630 \mathrm{~K}$. (b) Evolution with temperature of $\mathrm{C}_{4}$ hydroperoxide signals (in arbitrary units) ( $P=1 \mathrm{~atm}, \varphi=1, \tau=6 \mathrm{~s}$, fuel inlet mole fraction $=0.04)$.

The experiments with hexane isomers showed that, for a given fuel size, the more branched the reactant, the higher the temperature of ketohydroperoxide appearance. This measurement confirmed experimentally for the first time a fact postulated a long time ago from global reactivity experimental studies and modeling [18-20]: ketohydroperoxides derived from a series of two isomerizations which are disfavored for highly branched species [43]. Note also that while Eskola et al. [85] have detected ketohydroperoxides for $n$-butane, they have not reported them for iso-butane [86].

An attempt to quantify $C_{4}$ alkylhydroperoxides and ketohydroperoxides has been performed in the case of $n$-butane considering that these species have the same photoionization cross section as $\mathrm{C}_{4} \mathrm{H}_{8} \mathrm{O}$ compounds. This was taken to be equal to that of tetrahydrofuran, since all these $C_{4}$ oxygenated compounds have a similar ionization energy (see Figure 14). The largest mole fraction obtained was around $70 \mathrm{ppm}$ for butylhydroperoxides, with around $20 \mathrm{ppm}$ for butylketohydroperoxides [42]. An 
attempt at modeling showed an overestimation by factor of about 2 for butylhydroperoxides and about 5 for butylketohydroperoxides [42], which is not really surprising taking into account the very low stability of these molecules.

Hydrogen peroxide was also detected during these experiments [42], but since no accurate cross section is available the related quantification cannot be trusted. Note that the cross section of this relatively unstable molecule would be very difficult to determine due to the problems of accurately measuring $\mathrm{H}_{2} \mathrm{O}_{2}$ concentrations.

\section{Analysis of Diones and Related Species}

Clear proof of the formation of species with two carbonyl functions (diones) was obtained from SVUV-PIMS experiments in the case of all the alkanes which can easily lead to the formation of ketohydroperoxides ( $n$-butane [42], all the isomers of hexane reactive under the studied conditions [43], and $n$-heptane [24]). As for ketohydroperoxides, it was observed during the oxidation of hexane isomers [43] that the more branched the reactant, the higher the temperature of appearance of the signal corresponding to diones and the lower the maximum value.

Signals about 10 times lower have been recorded for species with a mass $M+2$ than for diones from $n$-butane [41] and hexane isomers [43]. These species were not observed for $n$-heptane [24], probably due to the too high dilution used (see Table 1). These species have been identified in the case of $n$-butane as being 3-hydroxybutanone and 3-hydroxybutanal [41] by a comparison of their ionization energies to values calculated using the quantum mechanics methods. These species could also be derived from ketohydroperoxides.

The photoionization efficiency spectra at $m / z 86$ and 88 are given in Figure 14a, and an example of the signals obtained at these $m / z$ values during $n$-butane oxidation is displayed in Figure 15 . Figure 15 also shows predicted mole fractions computed using a model including detailed pathways for the decomposition of the alkoxy radicals obtained by breaking the $\mathrm{O}-\mathrm{OH}$ bond in ketohydroperoxides. These alkoxy radicals can react by $\beta$-scission of a $\mathrm{C}-\mathrm{H}$ or a $\mathrm{C}-\mathrm{C}$ bond or by disproportionation with $\mathrm{HO}_{2} \bullet$ radicals. The two last reactions lead to the formations of diones and species with a carbonyl and a hydroxyl function, respectively. With this model, the shape of the signal temperature evolutions is satisfactorily reproduced. 


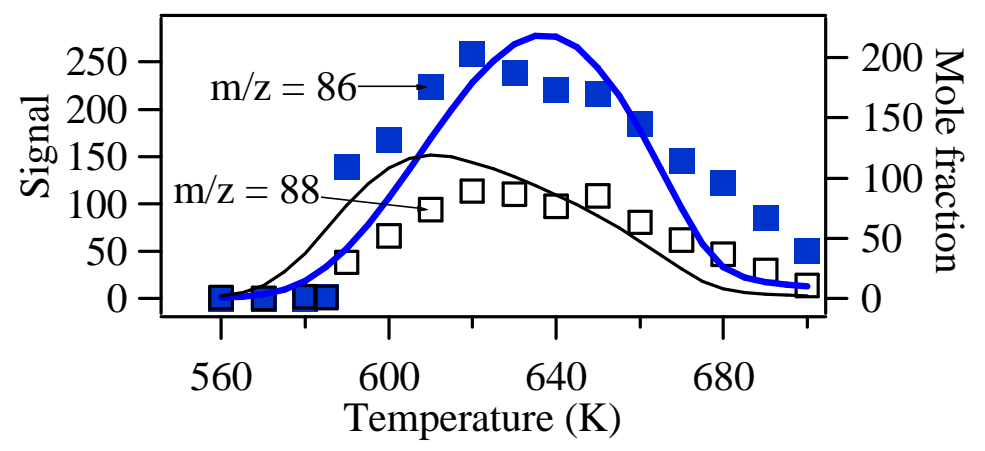

Figure 15. Evolution with temperature of the signal (in arbitrary units) of diones (filled squares) and species with a carbonyl and an alcohol function (open squares) from SVUV-MS analysis of the JSR oxidation of $n$-butane [40-42], comparison with predicted mole fractions $(P=1 \mathrm{~atm}, \varphi=1, \tau=6 \mathrm{~s}$, fuel inlet mole fraction $=0.04$ ).

Modeling investigations were also performed to reproduce the mole fraction profile of diones during the oxidation of $n$-heptane. Herbinet et al. [24] have proposed different channels to form diones from ketohydroperoxides. A first channel consists of the direct molecular elimination of water from ketohydroperoxides to form diones and $\mathrm{H}_{2} \mathrm{O}$. These authors also considered reactions of decomposition by $\beta$-scission and by isomerization, followed by an $\mathrm{H}$-abstraction by $\mathrm{O}_{2}$, from the alkoxy radicals obtained by breaking of the $\mathrm{O}-\mathrm{OH}$ bond in ketohydroperoxides. The shape of the predicted mole fraction profile was similar to that obtained in experiments, but mole fractions were underestimated by a factor of 40 . More work is needed to fully understand the formation of these species and the fate of ketohydroperoxides. In addition, if more quantitative comparisons are desired, a method to evaluate the photoionization cross-sections of these species needs to be found.

\section{Analysis of Carboxylic Acids}

Carboxylic acids have also been quantified by SVUV-PIMS experiments. Acetic acid has been measured for propane [36], $n$-butane [42] (see Figure 12), hexane isomers [43], and $n$-heptane [24] oxidation. Propanoic acid has been measured only in the cases of $n$-hexane [43] and $n$-heptane [24] as reactants. Cross sections of acetic and propanoic acids can be found in [24].

Herbinet et al. [24] added a submechanism to their $n$-heptane model to account for the formation of acetic and propanoic acids from aldehydes through peroxyacyl radicals. Figure 16a displays the sequence of reactions from acetaldehyde to acetic acid. The first step is the loss of the aldehydic $\mathrm{H}$-atom by $\mathrm{H}$-atom abstraction. The second step is the addition of this radical to molecular oxygen to form a peroxyacyl radical. This last radical reacts by termination with $\mathrm{HO}_{2} \bullet$ radicals to yield acetic acid 
and ozone. This sequence of reactions allowed good prediction of the mole fractions of carboxylic acids measured during the oxidation of $n$-butane [91], $n$-hexane [43], and $n$-heptane [24], but failed in the case of propane [36]. Another mechanism of formation of acids through reactions of ketohydroperoxides was recently proposed by Jalan et al. [92] (see Figure 16b), but this has not yet been tested for predicting acid formation in a JSR.

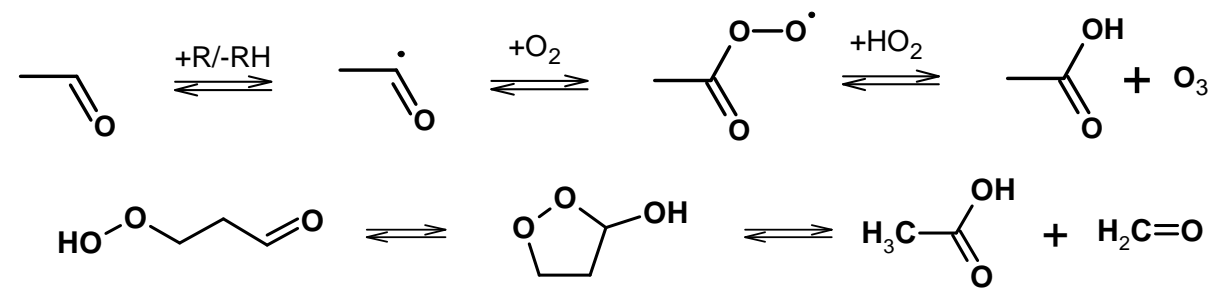

Figure 16. Two possible ways of formation of acetic acid: (a) from acetaldehyde via a peroxyacyl radical [24] and (b) from ketohydroperoxide [92].

Figure 17 shows fuel normalized (by inlet fuel mole fraction) mole fractions of acetic acid for various $\mathrm{C}_{3}$ to $\mathrm{C}_{7}$ alkanes. The formation of these compounds increases more significantly with the size of the linear reactants than the formation of acetaldehyde. As the ability to produce ketohydroperoxides through isomerizations is related to the size of the linear reactants, this supports the pathway of formation of acids from ketohydroperoxides proposed by Jalan et al. [92], rather than only a channel from acetaldehyde as suggested by Herbinet et al. [24].
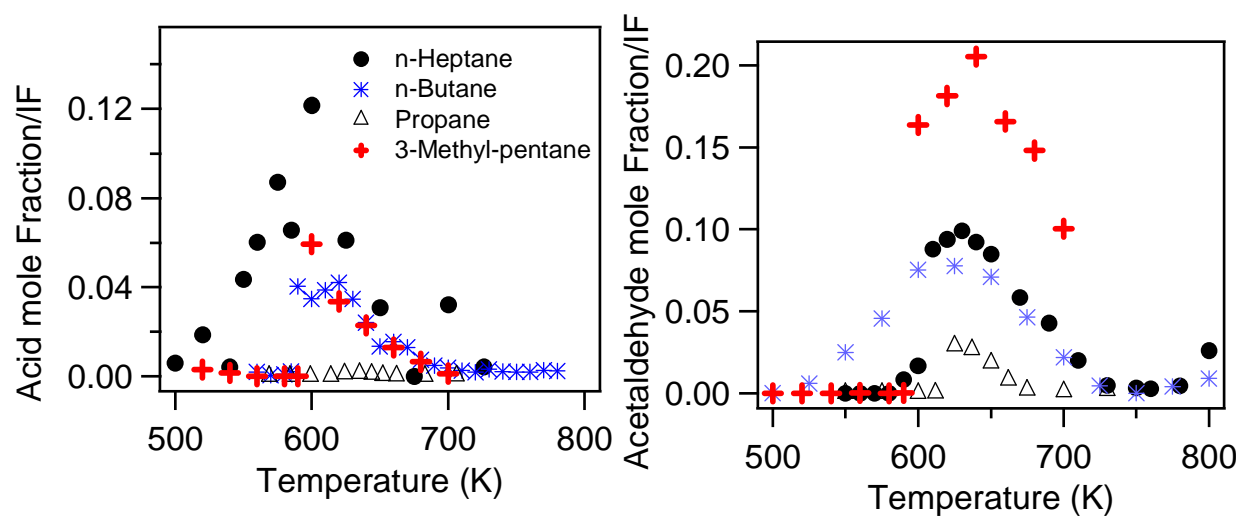

Figure 17. Evolution with temperature of fuel normalized mole fractions of acids (SVUV-PIMS analysis) and acetaldehyde during the JSR oxidation of propane (maximum conversion around 25\%) [36], $n$-butane (maximum conversion around 50\%) [42], 3-methyl-pentane (maximum conversion around 50\%)[43], and $n$-heptane (maximum conversion around 50\%)[24] (the normalization factor IF is the fuel inlet mole fraction) 
The fact that the normalized mole fractions of acetic acid obtained from 3-methyl-pentane lies between those from $n$-butane and $n$-heptane, whereas the formation of acetaldehyde from 3-methylpentane significantly exceeds that from $n$-heptane, also supports the theory of Jalan et al. [92]. This recent theory is also endorsed by the fact that no acid formation has been observed from 2,2dimethylpentane, which leads to maximum ketohydroperoxide signal some 15 times lower than 3methylpentane for the same fuel inlet concentration [43]. However, in the NTC zone (around $700 \mathrm{~K}$ ), where $n$-hexane still displays some reactivity, significant acid formation is observed together with high acetaldehyde formation [43].

\section{Comparison between Results Obtained by GC and SVUV-PIMS}

In most cases, a good agreement has been found for species that can be analyzed using both methods, as is shown in Figure 18, with maximum deviations up to a factor of 2 in the worst cases. These deviations can often be explained by fragment production when SVUV-PIMS mole fractions are larger than GC ones, as for example acetaldehyde in Figure 18. Larger deviations were observed during the oxidation of $n$-heptane in the low-temperature region: The mole fraction profiles obtained by GC for some species, such as carboxylic acids and diones, differed a lot from those obtained using SVUV-PIMS as shown in Figure 19.
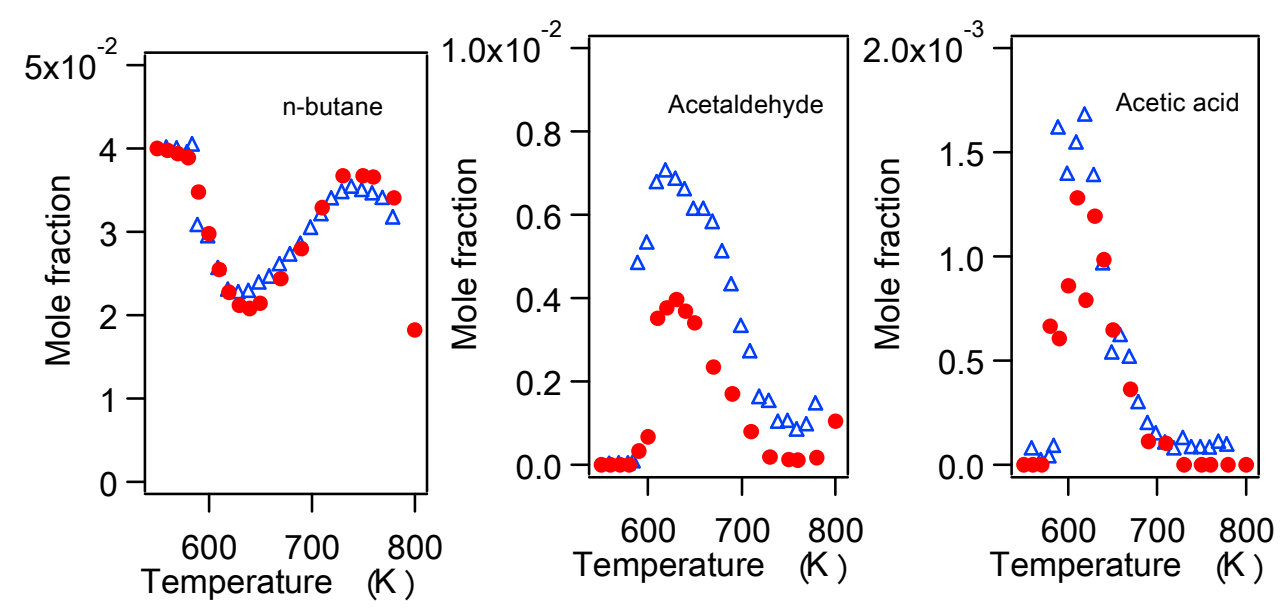

Figure 18. Examples of a comparison between results obtained by two methods ( $\bullet$ gas chromatography; $\triangle$ SVUV-PIMS data) during $n$-butane JSR oxidation [42] $(P=1 \mathrm{~atm}, \varphi=1, \tau=6 \mathrm{~s}$, fuel inlet mole fraction $=0.04$ ). 

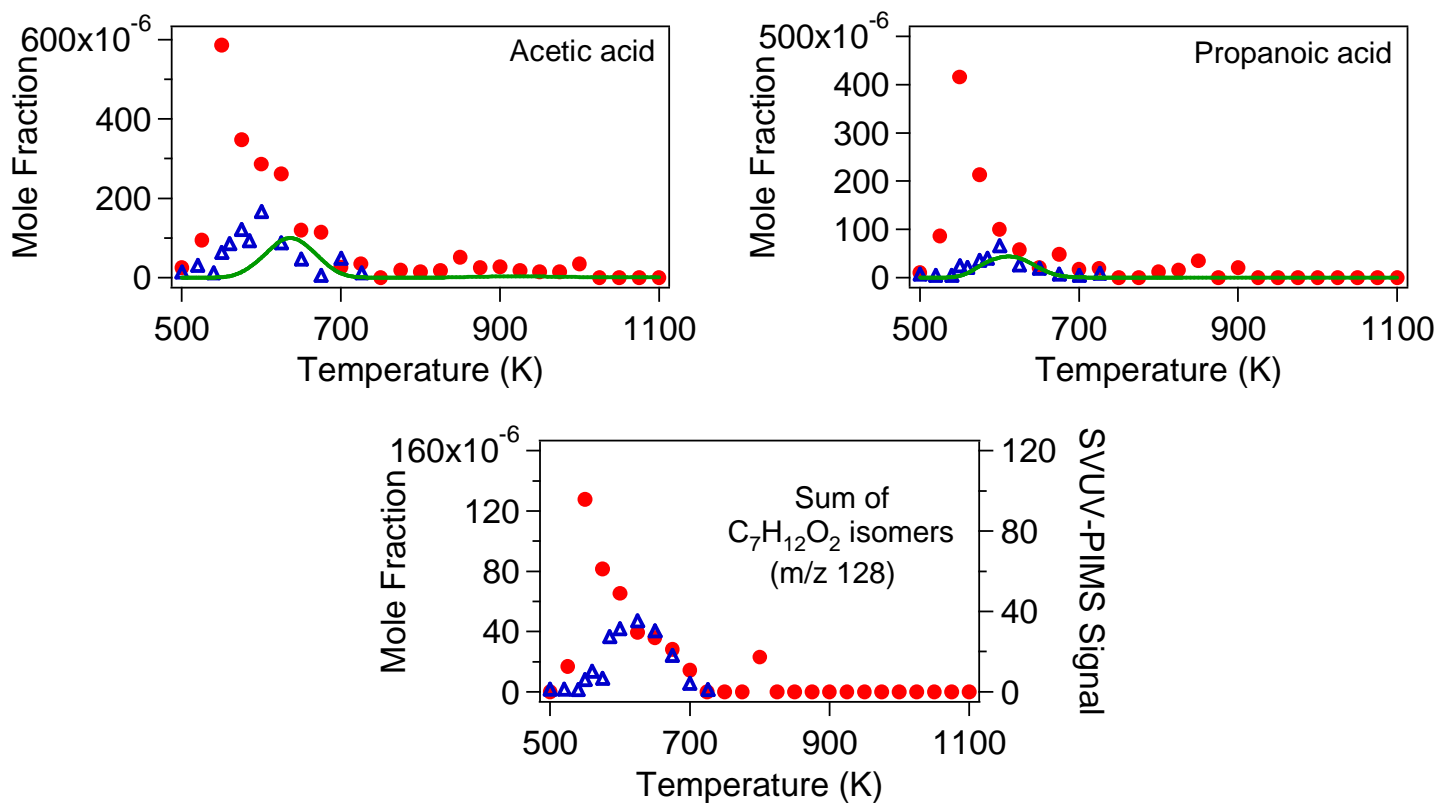

Figure 19. Mole fraction profiles of carboxylic acids and diones obtained by two methods ( $\bullet$ gas chromatography; $\triangle$ SVUV-PIMS data) during the oxidation of $n$-heptane [24] $(P=1 \mathrm{~atm}, \varphi=1, \tau=2 \mathrm{~s}$, inlet mole fraction $=0.005$ ).

It has been proposed that these deviations may be due to reactions occurring in the heated transfer line between the outlet of the reactor and the gas chromatographs or to sampling problems for high boiling point products. Consequently, the data that should be trusted for these species are those obtained using SVUV-PIMS, for which direct sampling in the gas phase is performed through a molecular beam.

\section{Knowledge Gained from Studies Using Optical Diagnostics}

Optical methods are currently used to probe combustion products in flames [93] and in shock tubes [4]. Fourier transform infrared (FTIR) spectroscopy has been long used in connection with JSR to probe $\mathrm{CO}, \mathrm{CO}_{2}, \mathrm{H}_{2} \mathrm{O}, \mathrm{NO}, \mathrm{NO}_{2}$, and $\mathrm{CH}_{2} \mathrm{O}$, e.g., [94]. In the past two years, two other methods, which are currently used to analyze atmospheric composition and chemistry [95-97], have been used to probe species during the JSR hydrocarbon oxidation: continuous-wave cavity ring-down spectroscopy (cW-CRDS) and fluorescence assay by gas expansion (FAGE). Similarly to the use of SVUV-PIMS $[40,42]$, the goal of coupling JSR with these optical methods was to obtain data about species that cannot be analyzed by classical methods. 


\section{Continuous-Wave Cavity Ring-Down Spectroscopy}

Cavity ring-down spectroscopy (CRDS) has already been used for several years to analyze intermediates formed in flames [98]. Bahrini et al. used cw-CRDS to analyze species formed during the JSR oxidation of methane [99] and $n$-butane $[37,38]$. A photograph of the apparatus is shown in Figure 20.

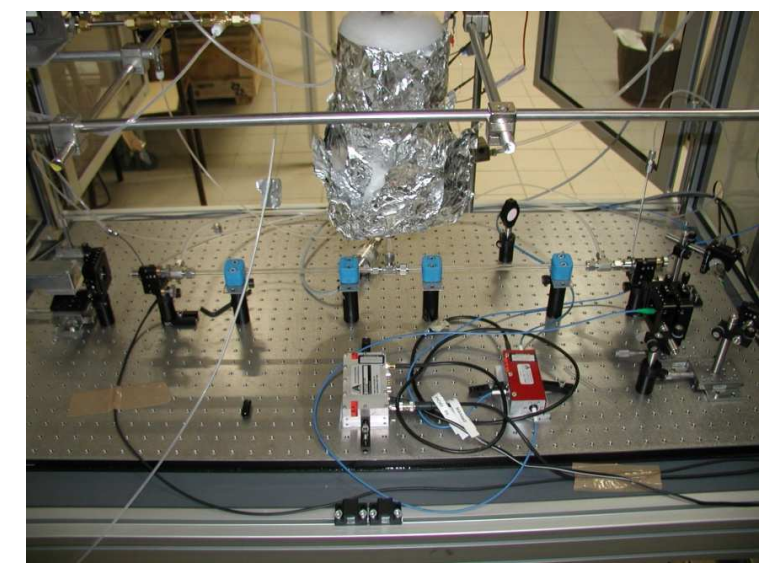

Figure 20. Photograph of the cw-CRDS cell coupled to a JSR [99].

CW-CRDS relies on the absorption of species in the near infrared $\left(6620-6644 \mathrm{~cm}^{-1}\right)$. Sampling is performed in the gas phase, thanks to a sonic probe $[7,99]$ connected to the cell working at low pressure (a few Torr). The cell is a glass tube with two high-reflectivity mirrors at its extremities. A diode laser pulse enters the cavity by one extremity, and the signal exiting the other extremity is recorded by an avalanche photodiode as a function of time. The concentration of absorbing species can be deduced from the ring-down time, which is obtained by fitting the exponential decay of the signal [99].

Species detected during the low-temperature oxidation of $n$-butane $[37,38]$ were formaldehyde $\left(\mathrm{CH}_{2} \mathrm{O}\right)$, water, ethylene, and hydrogen peroxide $\left(\mathrm{H}_{2} \mathrm{O}_{2}\right)$. As described previously in this text, $\mathrm{H}_{2} \mathrm{O}_{2}$ is a key compound in the chemistry involved in the low-temperature regime, which had never been quantified previously. In the case of hydrogen peroxide, the absorption sections in the near infrared region were not known from the literature and were therefore obtained from separate kinetic experiments using laser photolysis coupled to cw-CRDS. Bahrini et al. [99] also focused on the detection of another key intermediate in the low-temperature oxidation of hydrocarbons: the $\mathrm{HO}_{2} \bullet$ radical, which gives a well-structured spectrum in the wavelength range investigated. However, they were unable to detect any trace of this radical during their experiments. This was doubtless due to wall losses in the cell and probe. 
Figure 21 displays the mole fraction profiles recorded for hydrogen peroxide during the oxidation of $n$-butane, as well as data computed using a detailed kinetic model [38]. Bahrini et al. [37,38] observed that data were well reproduced in the low-temperature region, but that the model overestimated hydrogen peroxide mole fractions at high temperatures. Sensitivity analyses showed that uncertainties in homogeneous reactions could not explain the observed differences. The inclusion in the model of wall reactions, involving $\mathrm{HO}_{2} \bullet$ radical removal to give $\mathrm{H}_{2} \mathrm{O}_{2}$ and $\mathrm{O}_{2}$ as proposed by Porter et al. [100] and using a fitted rate constant (the dotted line in Figure 21) allowed a better match between experimental and computed data. The main impact of wall reactions in the model, apart from a large reduction in the predicted $\mathrm{H}_{2} \mathrm{O}_{2}$ maximum mole fraction, is only a shift of around $20 \mathrm{~K}$ in the reactivity between 800 and $850 \mathrm{~K}$ (as shown in Figure 21). The same shift can be observed in the profiles of most other oxidation products. Soon after the work of Bahrini et al. [37], Guo et al. [6] quantified $\mathrm{H}_{2} \mathrm{O}_{2}$ during the low-temperature oxidation of dimethyl ether in a flow reactor using MS, with the previously mentioned uncertainties related to calibration.

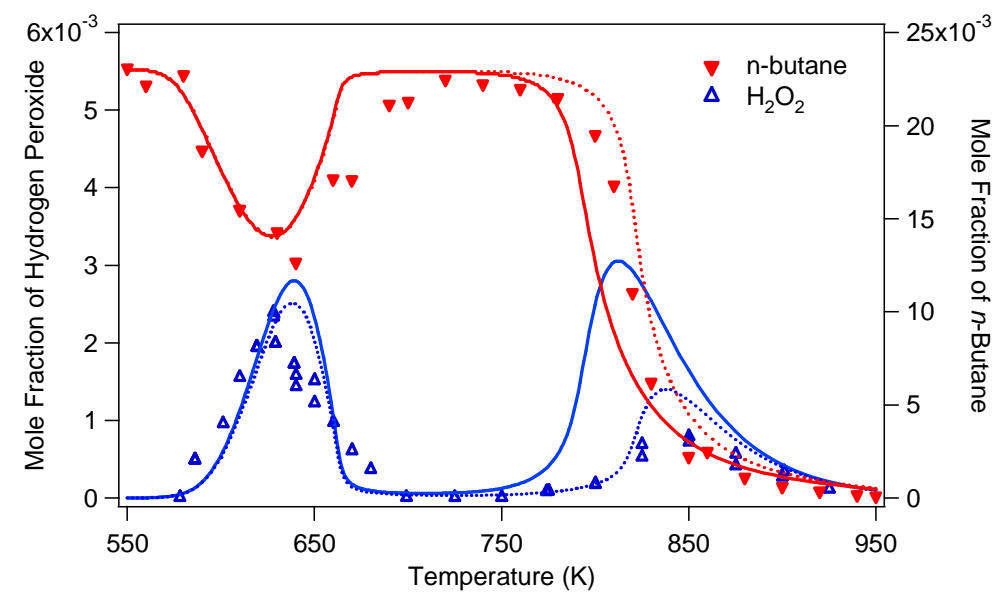

Figure 21. Mole fraction profiles of hydrogen and $n$-butane recorded in the oxidation of $n$-butane $[37,38]$. Symbols correspond to experimental data $(P=1 \mathrm{~atm}, \varphi=1, \tau=6 \mathrm{~s}$, fuel inlet mole fraction $=$ 0.023 ) and lines to data computed using detailed kinetic model (solid line: initial model; dotted line: model with wall reactions).

\section{Fluorescence Assay by Gas Expansion}

FAGE was initially developed for the quantification of hydroxyl $(\mathrm{HO} \bullet)$ and hydroperoxyl $\left(\mathrm{HO}_{2} \bullet\right)$ radicals in the atmosphere [97]. It has been coupled to a JSR by Blocquet et al. [39] to quantify these radicals during low-temperature oxidation of $n$-butane. This method is based on the detection of $\bullet \mathrm{OH}$ radicals by laser-induced fluorescence at $308 \mathrm{~nm}$. The detection of $\mathrm{HO}_{2} \bullet$ radicals is indirect: these radicals are converted to $\bullet \mathrm{OH}$ radicals by a reaction with NO in the measurement cell. The Nancy JSR was adapted 
for coupling to the FAGE system by pumping the gas exhaust from the usual outlet tube (see Figure 3) into an orifice with a diameter of $7 \mathrm{~mm}$. At the center of this was located the stainless steel cone with an orifice of $400 \mu \mathrm{m}$ : the FAGE inlet. The calibration method had to be adapted to handle the large JSR radical concentrations (ppm) compared to the typical very low atmospheric ones (ppt) [39] and is certainly subject to large uncertainties.

Figure 22 displays the mole fraction profiles of $\bullet \mathrm{OH}$ and $\mathrm{HO}_{2} \bullet$ radicals measured using this technique during the JSR oxidation of $n$-butane [39] (conditions are the same as those used to obtain the results presented in Figure 21). A relatively good agreement was obtained between experimental profiles and data computed using a detailed kinetic model [39].



Figure 22. Mole fraction profiles of $\bullet \mathrm{OH}$ and $\mathrm{HO}_{2} \bullet$ radicals measured by fluorescence assay by gas expansion in the oxidation of $n$-butane in a JSR [39]. Symbols correspond to experimental data $(P=1$ atm, $\varphi=1, \tau=6 \mathrm{~s}$, fuel inlet mole fraction $=0.023$ ) and lines to data computed using a detailed kinetic model.

Baulch et al. [101] observed temperature and $\bullet \mathrm{OH}$ radical oscillations in a CSTR in 1991 during the oxidation of hydrogen and carbon monoxide using laser absorption. However, the results shown in Figure 22 are the first ones obtained for the case of $\bullet \mathrm{OH}$ radicals during the low-temperature isothermal oxidation of an organic compound. In the case of $\mathrm{HO}_{2} \bullet$ radicals, in 2013, Brumfield et al. [102] had quantified them during the oxidation of dimethyl ether in a flow tube. 


\section{Conclusions and Perspectives}

The present paper summarizes and discusses the recent experiments that have been performed using a JSR to study the low-temperature oxidation of organic compounds. It can be seen that in the past 5 years the range of minor products that can be quantified from JSR has considerably been extended, to include the following:

- $\bullet \mathrm{OH}$ and $\mathrm{HO}_{2} \bullet$ radicals,

- hydrogen peroxide,

- $\mathrm{C}_{2}-\mathrm{C}_{3}$ carboxylic acids,

- cyclic ethers with a three-, four- or six-membered ring,

- hydrocarbons with two carbonyl groups (diones),

- hydroalkylperoxides, including ketohydroperoxides.

It should be noted that the range of species detected is considerably larger than the range of species that can be accurately quantified, even for relatively abundant species, such as diones. Progress is needed to find ways to more accurately quantify such compounds.

While progress can still be made in producing more accurate related rate constants, the formation of hydrogen peroxide, hydroalkylperoxides of the same size as the reactant, and all types of ethers, can be reproduced by detailed kinetic models to within a factor usually of less than 5 and often better. Nevertheless, this is not the case for other stable products. This shows that the involved formation pathways are certainly close to being fully identified for the first type of products, but not for the second. More work is needed to quantify and to better understand the chemistry involved in the formation of compounds with two carbonyl groups and of carboxylic acids.

Most of the studies that aim to extend the range of products that can be quantified during JSR studies have been carried out for linear and branched alkanes. More studies of this type are required for other hydrocarbons (alkenes, cycloalkanes, aromatics) and oxygenated compounds, especially those for which low-temperature reactivity is expected, such as large alcohols and esters.

It is also important to better understand the secondary reactions of the carbon-containing products listed above, especially cyclic ethers and aldehydes, which are formed in significant amounts. Experimental studies should be performed where clear results are easily accessible, with theoretical calculations for other cases. 


\section{Acknowledgments}

Many of the results presented in this paper were obtained from studies supported by the European Commission through the "Clean ICE" Advanced Research Grant of the European Research Council. The authors thank Professor Fei Qi and Dr. Christa Fittschen for the fruitful collaborations that have allowed some of the results presented here to be obtained.

\section{References}

(1) Dec, J. E. Proc. Combust. Inst. 2009, 32, 2727-2742.

(2) Battin-Leclerc, F.; Blurock, E.; Bounaceur, R.; Fournet, R.; Glaude, P.-A.; Herbinet, O.; Sirjean, B.; Warth, V. Chem. Soc. Rev. 2011, 40, 4762-4782.

(3) Minetti, R.; Carlier, M.; Ribaucour, M.; Therssen, E.; Sochet, L. R. Combust. Flame 1995, 102, $298-309$.

(4) Haylett, D. R.; Davidson, D. F.; Cook, R. D.; Hong, Z.; Ren, W.; Pyun, S. H.; Hanson, R. K. Proc. Combust. Inst. 2013, 34, 369-376.

(5) Natelson, R. H.; Kurman, M. S.; Cernansky, N. P.; Miller, D. L. Combust. Flame 2011, 158, 2325-2337.

(6) Guo, H.; Sun, W.; Haas, F. M.; Farouk, T.; Dryer, F. L.; Ju, Y. Proc. Combust. Inst. 2013, 34, 573-581.

(7) Herbinet, O.; Dayma, G. In Cleaner Combustion; Battin-Leclerc, F.; Simmie, J. M.; Blurock, E., Eds.; Green Energy and Technology; Springer London, 2013; pp. 183-210.

(8) Ciezki, H. K.; Adomeit, G. Combust. Flame 1993, 93, 421-433.

(9) Minetti, R.; Carlier, M.; Ribaucour, M.; Therssen, E.; Sochet, L. R. Symp. Int. Combust. 1996, 26, 747-753.

(10) Curran, H. J.; Gaffuri, P.; Pitz, W. J.; Westbrook, C. K. Combust. Flame 1998, 114, 149-177.

(11) Ranzi, E.; Gaffuri, P.; Faravelli, T.; Dagaut, P. Combust. Flame 1995, 103, 91-106.

(12) Buda, F.; Bounaceur, R.; Warth, V.; Glaude, P. A.; Fournet, R.; Battin-Leclerc, F. Combust. Flame 2005, 142, $170-186$.

(13) Westbrook, C. K.; Pitz, W. J.; Herbinet, O.; Curran, H. J.; Silke, E. J. Combust. Flame 2009, 156, 181-199.

(14) Hakka, M. H.; Glaude, P.-A.; Herbinet, O.; Battin-Leclerc, F. Combust. Flame 2009, 156, 2129-2144.

(15) Bax, S.; Hakka, M. H.; Glaude, P.-A.; Herbinet, O.; Battin-Leclerc, F. Combust. Flame 2010, 157, $1220-1229$.

(16) Westbrook, C. K.; Naik, C. V.; Herbinet, O.; Pitz, W.; Mehl, M.; Sarathy, S. M.; Curran, H. J. Combust. Flame 2011, $158,742-755$.

(17) Battin-Leclerc, F.; Warth, V.; Bounaceur, R.; Husson, B.; Herbinet, O.; Glaude, P. A. Proc. Combust. Inst. 2015, 10.1016/j.proci.2014.05.087.

(18) Walker, R. W.; Morley, C. Chapter 1 Basic chemistry of combustion; 1997; Vol. 35.

(19) Battin-Leclerc, F. Prog. Energy Combust. Sci. 2008, 34, 440-498.

(20) Zádor, J.; Taatjes, C. A.; Fernandes, R. X. Prog. Energy Combust. Sci. 2011, 37, 371-421.

(21) Tran, L. S.; Sirjean, B.; Glaude, P.-A.; Fournet, R.; Battin-Leclerc, F. Energy 2012, 43, 4-18.

(22) Battin-Leclerc, F.; Rodriguez, A.; Husson, B.; Herbinet, O.; Glaude, P.-A.; Wang, Z.; Cheng, Z.; Qi, F. J. Phys. Chem. A $2014,118,673-683$.

(23) Herbinet, O.; Husson, B.; Ferrari, M.; Glaude, P.-A.; Battin-Leclerc, F. Proc. Combust. Inst. 2013, 34, $297-305$.

(24) Herbinet, O.; Husson, B.; Serinyel, Z.; Cord, M.; Warth, V.; Fournet, R.; Glaude, P.-A.; Sirjean, B.; Battin-Leclerc, F.; Wang, Z.; Xie, M.; Cheng, Z.; Qi, F. Combust. Flame 2012, 159, 3455-3471.

(25) Bounaceur, R.; Da Costa, I.; Fournet, R.; Billaud, F.; Battin-Leclerc, F. Int. J. Chem. Kinet. 2005, 37, $25-49$. 
(27) Dagaut, P.; Cathonnet, M.; Boettner, J. C.; Gaillard, F. Combust. Flame 1988, 71, 295-312.

(28) Westbrook, C. K.; Pitz, W. J.; Thornton, M. M.; Malte, P. C. Combust. Flame 1988, 72, 45-62.

(29) Baulch, D. L.; Griffiths, J. F.; Pappin, A. J.; Sykes, A. F. Combust. Flame 1988, 73, 163-185.

(30) Gibson, C.; Gray, P.; Griffiths, J. F.; Hasko, S. M. Symp. Int. Combust. 1985, 20, 101-109.

(31) Battin-Leclerc, F.; Marquaire, P. M.; Baronnet, F.; Côme, G. M. J. Anal. Appl. Pyrolysis 1989, 16, 345-354.

(32) Chakir, A.; Cathonnet, M.; Boettner, J. C.; Gaillard, F. Symp. Int. Combust. 1989, 22, 873-881.

(33) Thorton, M. M.; Malte, P. C.; Crittenden, A. L. Symp. Int. Combust. 1988, 21, 979-989.

(34) Yahyaoui, M.; Djebaili-Chaumeix, N.; Dagaut, P.; Paillard, C.; Gail, S. Combust. Flame 2006, 147, 67-78.

(35) Bounaceur, R.; Warth, V.; Sirjean, B.; Glaude, P. A.; Fournet, R.; Battin-Leclerc, F. Proc. Combust. Inst. 2009, 32, 387394.

(36) Cord, M.; Husson, B.; Lizardo Huerta, J. C.; Herbinet, O.; Glaude, P.-A.; Fournet, R.; Sirjean, B.; Battin-Leclerc, F.; Ruiz-Lopez, M.; Wang, Z.; Xie, M.; Cheng, Z.; Qi, F. J. Phys. Chem. A 2012, 116, 12214-12228.

(37) Bahrini, C.; Herbinet, O.; Glaude, P.-A.; Schoemaecker, C.; Fittschen, C.; Battin-Leclerc, F. J. Am. Chem. Soc. 2012, 134, 11944-11947.

(38) Bahrini, C.; Morajkar, P.; Schoemaecker, C.; Frottier, O.; Herbinet, O.; Glaude, P.-A.; Battin-Leclerc, F.; Fittschen, C. Phys. Chem. Chem. Phys. 2013, 15, 19686-19698.

(39) Blocquet, M.; Schoemaecker, C.; Amedro, D.; Herbinet, O.; Battin-Leclerc, F.; Fittschen, C. Proc. Natl. Acad. Sci. 2013, 110, 20014-20017.

(40) Battin-Leclerc, F.; Herbinet, O.; Glaude, P.-A.; Fournet, R.; Zhou, Z.; Deng, L.; Guo, H.; Xie, M.; Qi, F. Angew. Chem. Int. Ed. 2010, 49, 3169-3172.

(41) Battin-Leclerc, F.; Herbinet, O.; Glaude, P.-A.; Fournet, R.; Zhou, Z.; Deng, L.; Guo, H.; Xie, M.; Qi, F. Proc. Combust. Inst. 2011, 33, 325-331.

(42) Herbinet, O.; Battin-Leclerc, F.; Bax, S.; Gall, H. L.; Glaude, P.-A.; Fournet, R.; Zhou, Z.; Deng, L.; Guo, H.; Xie, M.; Qi, F. Phys. Chem. Chem. Phys. 2011, 13, 296-308.

(43) Wang, Z.; Herbinet, O.; Cheng, Z.; Husson, B.; Fournet, R.; Qi, F.; Battin-Leclerc, F. J. Phys. Chem. A 2014, 118, 55735594.

(44) Dagaut, P.; Reuillon, M.; Cathonnet, M. Combust. Sci. Technol. 1994, 95, 233-260.

(45) Dagaut, P.; Reuillon, M.; Cathonnet, M. Combust. Flame 1995, 101, 132-140.

(46) Cavaliere, A.; Ciajolo, A.; D’Anna, A.; Mercogliano, R.; Ragucci, R. Combust. Flame 1993, 93, 279-286.

(47) Dagaut, P.; Reuillon, M.; Cathonnet, M. Combust. Sci. Technol. 1994, 103, 315-336.

(48) D’Anna, A.; Mercogliano, R.; Barbella, R.; Ciajolo, A. Combust. Sci. Technol. 1992, 83, 217-232.

(49) Husson, B.; Herbinet, O.; Glaude, P. A.; Ahmed, S. S.; Battin-Leclerc, F. J. Phys. Chem. A 2012, 116, 5100-5111.

(50) Sarathy, S. M.; Westbrook, C. K.; Mehl, M.; Pitz, W. J.; Togbe, C.; Dagaut, P.; Wang, H.; Oehlschlaeger, M. A.; Niemann, U.; Seshadri, K.; Veloo, P. S.; Ji, C.; Egolfopoulos, F. N.; Lu, T. Combust. Flame 2011, 158, 2338-2357.

(51) Karsenty, F.; Sarathy, S. M.; Togbé, C.; Westbrook, C. K.; Dayma, G.; Dagaut, P.; Mehl, M.; Pitz, W. J. Energy Fuels 2012, 26, 4680-4689.

(52) Sarathy, S. M.; Javed, T.; Karsenty, F.; Heufer, A.; Wang, W.; Park, S.; Elwardany, A.; Farooq, A.; Westbrook, C. K.; Pitz, W. J.; Oehlschlaeger, M. A.; Dayma, G.; Curran, H. J.; Dagaut, P. Combust. Flame 2014, 161, 1444-1459.

(53) Dagaut, P.; Reuillon, M.; Cathonnet, M. Combust. Sci. Technol. 1994, 103, 349-359.

(54) Biet, J.; Hakka, M. H.; Warth, V.; Glaude, P.-A.; Battin-Leclerc, F. Energy Fuels 2008, 22, 2258-2269. 

2013, 160, 2319-2332.

(56) Husson, B.; Herbinet, O.; Le Gall, H.; Battin-Leclerc, F. In European Combustion Meeting; Lund, Sweden, 2013.

(57) Husson, B.; Bounaceur, R.; Tanaka, K.; Ferrari, M.; Herbinet, O.; Glaude, P. A.; Fournet, R.; Battin-Leclerc, F.; Crochet, M.; Vanhove, G.; Minetti, R.; Tobin, C. J.; Yasunaga, K.; Simmie, J. M.; Curran, H. J.; Niass, T.; Mathieu, O.; Ahmed, S. S. Combust. Flame 2012, 159, 1399-1416.

(58) Dayma, G.; Gaïl, S.; Dagaut, P. Energy Fuels 2008, 22, 1469-1479.

(59) Zhang, K.; Togbé, C.; Dayma, G.; Dagaut, P. Combust. Flame 2014, 161, 818-825.

(60) Dayma, G.; Togbé, C.; Dagaut, P. Energy Fuels 2009, 23, 4254-4268.

(61) Glaude, P. A.; Herbinet, O.; Bax, S.; Biet, J.; Warth, V.; Battin-Leclerc, F. Combust. Flame 2010, 157, $2035-2050$.

(62) Dayma, G.; Togbé, C.; Dagaut, P. Energy Fuels 2011, 25, 4986-4998.

(63) Mani Sarathy, S.; Park, S.; Weber, B. W.; Wang, W.; Veloo, P. S.; Davis, A. C.; Togbe, C.; Westbrook, C. K.; Park, O.; Dayma, G.; Luo, Z.; Oehlschlaeger, M. A.; Egolfopoulos, F. N.; Lu, T.; Pitz, W. J.; Sung, C.-J.; Dagaut, P. Combust. Flame 2013, $160,2712-2728$.

(64) Togbé, C.; Dagaut, P.; Mzé-Ahmed, A.; Diévart, P.; Halter, F.; Foucher, F. Energy Fuels 2010, 24, 5859-5875.

(65) Dagaut, P.; Boettner, J. C.; Cathonnet, M. Symp. Int. Combust. 1996, 26, 627-632.

(66) Dagaut, P.; Daly, C.; Simmie, J. S.; Cathonnet, M. Symp. Int. Combust. 1998, 27, 361-369.

(67) Stoehr, K. D.; Peters, N. Proc. Combust. Inst. 2014, 10.1016/j.proci.2014.06.145.

(68) Dagaut, P.; Koch, R.; Cathonnet, M. Combust. Sci. Technol. 1997, 122, 345-361.

(69) Veloo, P. S.; Dagaut, P.; Togbé, C.; Dayma, G.; Sarathy, S. M.; Westbrook, C. K.; Egolfopoulos, F. N. Combust. Flame 2013, 160, 1609-1626.

(70) David, R.; Matras, D. Can. J. Chem. Eng. 1975, 53, 297-300.

(71) Matras, D.; Villermaux, J. Chem. Eng. Sci. 1973, 28, 129-137.

(72) Ranzi, E.; Faravelli, T.; Gaffuri, P.; Sogaro, A.; Danna, A.; Ciajolo, A. Combust. Flame 1997, 108, $24-42$.

(73) Dagaut, P.; Cathonnet, M.; Rouan, J. P.; Foulatier, R.; Quilgars, A.; Boettner, J. C.; Gaillard, F.; James, H. J. Phys. [E] 1986, 19, 207-209.

(74) Azay, P.; Côme, G.-M. Ind. Eng. Chem. Process Des. Dev. 1979, 18, 754-756.

(75) Herbinet, O.; Marquaire, P.-M.; Battin-Leclerc, F.; Fournet, R. J. Anal. Appl. Pyrolysis 2007, 78, 419-429.

(76) Glaude, P. A.; Battin-Leclerc, F.; Judenherc, B.; Warth, V.; Fournet, R.; Côme, G. M.; Scacchi, G.; Dagaut, P.; Cathonnet, M. Combust. Flame 2000, 121, 345-355.

(77) Baker, R. R.; Baldwin, R. R.; Walker, R. W. J. Chem. Soc. Faraday Trans. 1 Phys. Chem. Condens. Phases 1975, 71, 756-779.

(78) Baldwin, R. R.; Hisham, M. W. M.; Walker, R. W. J. Chem. Soc. Faraday Trans. 1 Phys. Chem. Condens. Phases 1982, 78, 1615-1627.

(79) DeSain, J. D.; Taatjes, C. A.; Miller, J. A.; Klippenstein, S. J.; Hahn, D. K. Faraday Discuss. 2002, 119, $101-120$.

(80) Sharma, S.; Raman, S.; Green, W. H. J. Phys. Chem. A 2010, 114, 5689-5701.

(81) Villano, S. M.; Huynh, L. K.; Carstensen, H.-H.; Dean, A. M. J. Phys. Chem. A 2011, 115, 13425-13442.

(82) Villano, S. M.; Huynh, L. K.; Carstensen, H.-H.; Dean, A. M. J. Phys. Chem. A 2012, 116, 5068-5089.

(83) Cord, M.; Sirjean, B.; Fournet, R.; Tomlin, A.; Ruiz-Lopez, M.; Battin-Leclerc, F. J. Phys. Chem. A 2012, 116, 61426158.

(84) Herbinet, O.; Bax, S.; Glaude, P.-A.; Carré, V.; Battin-Leclerc, F. Fuel 2011, 90, 528-535.

(85) Eskola, A. J.; Welz, O.; Savee, J. D.; Osborn, D. L.; Taatjes, C. A. J. Phys. Chem. A 2013, 117, 12216-12235. 
(86) Welz, O.; Savee, J. D.; Eskola, A. J.; Sheps, L.; Osborn, D. L.; Taatjes, C. A. Proc. Combust. Inst. 2013, 34, 493-500.

(87) Chebbi, A.; Carlier, P. Atmos. Environ. 1996, 30, 4233-4249.

(88) McEnally, C. S.; Pfefferle, L. D.; Atakan, B.; Kohse-Hoeinghaus, K. Prog. Energy Combust. Sci. 2006, 32, $247-294$.

(89) Qi, F. Proc. Combust. Inst. 2013, 34, 33-63.

(90) Taatjes, C. A.; Hansen, N.; Mcllroy, A.; Miller, J. A.; Senosiain, J. P.; Klippenstein, S. J.; Qi, F.; Sheng, L. S.; Zhang, Y. W.; Cool, T. A.; Wang, J.; Westmoreland, P. R.; Law, M. E.; Kasper, T.; Kohse-Hoinghaus, K. Science 2005, 308, 1887-1889.

(91) Cord, M. Modélisation de la chimie de la combustion des alcanes et des alcènes à basse température par des approches de chimie quantique, Université de Lorraine: Nancy, 2013.

(92) Jalan, A.; Alecu, I. M.; Meana-Pañeda, R.; Aguilera-Iparraguirre, J.; Yang, K. R.; Merchant, S. S.; Truhlar, D. G.; Green, W. H. J. Am. Chem. Soc. 2013, 135, 11100-11114.

(93) Cheskis, S.; Goldman, A. Prog. Energy Combust. Sci. 2009, 35, 365-382.

(94) Dubreuil, A.; Foucher, F.; Mounaim-Rousselle, C.; Dayma, G.; Dagaut, P. Proc. Combust. Inst. 2007, 31, $2879-2886$.

(95) Clemitshaw, K. C. Crit. Rev. Environ. Sci. Technol. 2004, 34, 1-108.

(96) Parker, A. E.; Jain, C.; Schoemaecker, C.; Szriftgiser, P.; Votava, O.; Fittschen, C. Appl. Phys. B Lasers Opt. 2011, 103, 725-733.

(97) Amedro, D.; Miyazaki, K.; Parker, A.; Schoernaecker, C.; Fittschen, C. J. Environ. Sci.-China 2012, $24,78-86$.

(98) Mercier, X.; Therssen, E.; Pauwels, J. F.; Desgroux, P. Proc. Combust. Inst. 2005, 30, 1655-1663.

(99) Bahrini, C.; Herbinet, O.; Glaude, P.-A.; Schoemaecker, C.; Fittschen, C.; Battin-Leclerc, F. Chem. Phys. Lett. 2012, 534, 1-7.

(100) Porter, R.; Glaude, P.-A.; Buda, F.; Battin-Leclerc, F. Energy Fuels 2008, 22, 3736-3743.

(101) Baulch, D. L.; Griffiths, J. F.; Richter, R. Chem. Eng. Sci. 1991, 46, 2315-2322.

(102) Brumfield, B.; Sun, W.; Ju, Y.; Wysocki, G. J. Phys. Chem. Lett. 2013, 4, 872-876. 